Article

\title{
Analysis of Mycotoxins Contamination in Poultry Feeds Manufactured in Selected Provinces of South Africa Using UHPLC-MS/MS
}

\author{
Sharon Maphala Mokubedi ${ }^{1}{ }^{\mathbb{D}}$, Judith Zanele Phoku ${ }^{2}$, Rumbidzai Naledi Changwa ${ }^{1}$, \\ Sefater Gbashi ${ }^{1}$ and Patrick Berka Njobeh ${ }^{1, *(D)}$ \\ 1 Department of Biotechnology and Food Technology, Faculty of Science, University of Johannesburg, \\ P.O. Box 17011, Doornfontein Campus, Johannesburg, South Africa \\ 2 Agricultural Research Council, Onderstepoort Veterinary Institute, Toxicology and Ethnoveterinary \\ Medicine, Public Health and Zoonoses, Private Bag X05, Onderstepoort, Pretoria North 0110, South Africa \\ * Correspondence: pnjobeh@uj.ac.za; Tel.: +27-72-961-6685
}

Received: 12 June 2019; Accepted: 6 July 2019; Published: 2 August 2019

check for updates

\begin{abstract}
A total of 105 different types of poultry feed samples from South Africa were simultaneously analysed for the presence of 16 mycotoxins using ultra-high-performance liquid chromatography coupled to a triple quadrupole mass spectrometer (UHPLC-MS/MS). The data revealed the presence of 16 mycotoxins in the various poultry feed samples. Fumonisin $\mathrm{B}_{1}\left(\mathrm{FB}_{1}\right)$ was the most dominant recovered from $100 \%$ of samples analysed at concentrations ranging between 38.7 and $7125.3 \mu \mathrm{g} / \mathrm{kg}$. This was followed by zearalenone (ZEN) (range: $0.1-429 \mu \mathrm{g} / \mathrm{kg}$ ) and deoxynivalenol (DON) (range: $2.5-154 \mu \mathrm{g} / \mathrm{kg}$ ). Samples were also found to be contaminated with fumonisin $\mathrm{B}_{2}\left(\mathrm{FB}_{2}\right)$ (range: $0.7-125.1 \mu \mathrm{g} / \mathrm{kg}$ ), fumonisin $\mathrm{B}_{3}\left(\mathrm{FB}_{3}\right)$ (range: 0.1-125.1 $\left.\mu \mathrm{g} / \mathrm{kg}\right), \alpha$-zearalenol $(\alpha-Z E L)$ (range: $0.6-20 \mu \mathrm{g} / \mathrm{kg}$ ), $\beta$-zearalenol ( $\beta$-ZEL) (range: 0.2-22.1 $\mu \mathrm{g} / \mathrm{kg}$ ), 3-acetyldeoxynivalenol (3-ADON) (range: 0.1-12.9 $\mu \mathrm{g} / \mathrm{kg}$ ) and 15-acetyldeoxynivalenol (15-ADON) (range: $1.7-41.9 \mu \mathrm{g} / \mathrm{kg}$ ). Alternaria mycotoxin, i.e., Alternariol monomethyl ether (AME) was recovered in $100 \%$ of samples at concentrations that ranged from $0.3-155.5 \mu \mathrm{g} / \mathrm{kg}$. Aflatoxins (AFs) had an incidence rate of $92 \%$ with generally low concentration levels ranging from $0.1-3.7 \mu \mathrm{g} / \mathrm{kg}$. Apart from these metabolites, 2 type A trichothecenes (THs), i.e., HT-2 toxin (HT-2) (range: $0.2-5.9 \mu \mathrm{g} / \mathrm{kg}$ ) and T-2 toxin (T-2) (range: $0.1-15.3 \mu \mathrm{g} / \mathrm{kg}$ ) were also detected. Mycotoxin contamination in South African poultry feed constitutes a concern as correspondingly high contamination levels, such as those observed herein are likely to affect birds, which can be accompanied by severe health implications, thus compromising animal productivity in the country. Such exposures, primarily to more than one mycotoxin concurrently, may elicit noticeable synergistic and or additive effects on poultry birds.
\end{abstract}

Keywords: mycotoxins; poultry feeds; UHPLC-MS/MS; South Africa

Key Contribution: This study assessed the incidence and contamination levels of mycotoxins in poultry feed manufactured in some selected provinces of South Africa. The findings of this study will contribute effectively to the poultry industry and within the management of the feed supply chain.

\section{Introduction}

In basic terms, animals require an adequate supply of carbohydrates, proteins, fats/oils, vitamins, minerals, and water. However, the composition of raw materials in animal feeds varies from formulation to formulation and between different species [1]. In South Africa, the poultry industry is divided into two, i.e., the broiler industry, which supplies poultry meat, and the egg industry that is generally layer and breeder farm chickens for egg production [2]. While poultry feeds are largely composed of cereal 
grains, protein, and vitamin supplements [3], the most significant ingredients used in South African poultry feeds are maize, oilcake, soybeans and fishmeal [1]. The poultry industry in the country remains the second largest consumer of maize often used as the main ingredient in poultry feed formulation [2].

In most cases, feeds are produced and stored for a long period of time before distribution and this may endanger the quality for animal consumption. Poor composition of raw materials, high carbon, and moisture in feeds may very often lead to fungal and mycotoxin contamination [4-7]. Mycotoxins are well-known toxic secondary metabolites mainly produced by various filamentous fungal species of the Aspergillus, Fusarium, Penicillium, and Alternaria genera, which are commonly recognised as contaminants of food and feedstuffs $[7,8]$. Even though over 300 mycotoxins are known to occur under a wide range of climatic conditions, those that are significant due to health and economic significance in sub-Saharan Africa (SSA) are the aflatoxins (AFs), fumonisins (FUMs), in addition to ochratoxins (OTs) and trichothecenes (TH) [8,9]. The significance of these mycotoxins rests on their existence in food and feed above regulatory limits. Other than their presence in food and feed, emerging Alternaria mycotoxins such as alternariol monomethyl ether (AME), alternariol (AOH) and tenuazonic acid (TeA) are frequently encountered as contaminants of feed ingredients [10] that could occasionally find themselves in the final product. Although their contamination levels are generally low with limited toxicity data in chickens, their health risk cannot be completely excluded when noting their possible reproductive and immune system effects in both humans and animals [11-13].

Most cases related to chronic conditions result from the consumption of mycotoxins regularly at low doses, which go unnoticed especially since they can co-occur throughout the animal's developmental cycle, causing multiple diseases [3,14-17]. In poultry, the consumption of ochratoxin A (OTA) contaminated feed can result in ochratoxicosis, a general term for OTs causing disease, characterised by low egg production and poor weight gain $[3,5]$, whereas the consumption of AF contaminated feed or feedstuff results in the hepatic condition, aflatoxicosis, causing anorexia and affecting growth rates, decreasing egg production and increasing death rates [3,17]. Aflatoxins, which mostly flourish under tropical conditions, have the ability to cause extensive liver damage in poultry and other livestock [5]. The co-occurrence of FUMs, deoxynivalenol (DON), and zearalenone (ZEN) in poultry feed can possibly lead to symptoms such as reduced villus height in broiler chicks [14,16].

Feed represents one of the main aspects in poultry production. Both broilers and layers are effective in converting feed to food products $[15,18]$ and as such, there are high chances of the carry-over of mycotoxins into edible by-products from poultry bird fed with contaminated feeds. The situation of poultry feeds contaminated by mycotoxins is an eminent potential of carry-over affecting negatively poultry health and performance. Broiler and layer chickens in farms affected by mycotoxicosis have been seen to exhibit symptoms such as weight loss, reduced feed conversion competency, immunosuppression, failure to vaccination responses, low fertility, high chances of egg blood spots, kidney enlargement, pale fatty liver, gizzard erosions, increased incidence of leg malformations, visceral haemorrhages, inclusion body hepatitis and oral lesion $[7,15,18]$. Such conditions may negatively and seriously affect the poultry industry.

In South Africa, few studies on mycotoxins in poultry feed are reported, meaning that limited studies in monitoring them exist. Recently, a study on the dairy cattle feeds from the Gauteng Province of South Africa established the occurrence of 15 mycotoxins [19]. A study on compound feeds produced in South Africa reported FUMs as the most dominant mycotoxin that co-existed with ZEN and DON in $67 \%$ of all the samples analysed [8]. The survey on South African feed samples revealed the occurrence of $75 \%$ FUMs, $90 \%$ DON, $20 \%$ ZEN and $14 \%$ AFs [20]. The nature and presence of mycotoxins in South African animal feeds should be an on-going matter since some of these mycotoxins are found in animal products from animals that consume feeds contaminated with mycotoxins [21,22]. Despite an increased interest in mycotoxins contamination and their health effects, only a few studies covered the scope of mycobiota and mycotoxins in poultry feed in the country $[8,23,24]$.

Hence in this study, the most commonly encountered mycotoxins (AFs, FUMs, DON, ZEN, T-2 toxin and HT-2 toxin) including the Alternaria toxin, AME and derivatives of ZEN i.e., $\alpha$-ZEL 
and $\beta$-ZEL, and derivatives of DON i.e., 3-ADON and 15-ADON in poultry feed manufactured in South Africa were screened for multiple contamination using UHPLC-MS/MS. This was particularly important since the co-occurrence of these mycotoxins could synergistically act with one another to potentiate additional or at best synergistic toxic effects in animals, as reported elsewhere $[5,14]$.

\section{Results}

\subsection{Mycotoxin Identification}

The present study analysed 16 different mycotoxins in various poultry feed from some selected manufacturing sites as described subsequently in Section 5. Associated method validation parameters are presented in Table 1. The linearity coefficient of determination ranged from 0.9919 to 0.9999 , while the apparent recoveries for 16 mycotoxins extracted from each spiked matrix ranged from 73 to 132.3\%. Accordingly, 16 mycotoxins (raw data presented in Appendix A Table A3) were simultaneously analysed based on a multi-mycotoxin dilute and shoot method using UHPLC-MS/MS. The employed analytical method allowed for the accurate analysis of the targeted mycotoxins based on retention profiles and selected MS parameters in Table A2 (Appendix A).

Table 1. Quantification parameters based on calibration curves. Data display affiliated method for limits of quantification (LOQ) and limits of detection (LOD) for each mycotoxin.

\begin{tabular}{|c|c|c|c|c|c|}
\hline Compound & $\begin{array}{c}\text { Calibration Level } \\
(\mu \mathrm{g} / \mathrm{kg})\end{array}$ & $\begin{array}{c}\text { Spiking } \\
\text { Concentrations } \\
(\mu \mathrm{g} / \mathrm{kg})\end{array}$ & $\begin{array}{c}\text { Apparent } \\
\text { Recovery (\%) }\end{array}$ & $\begin{array}{c}\text { LOQ } \\
(\mu \mathrm{g} / \mathrm{kg})\end{array}$ & LOD $(\mu \mathrm{g} / \mathrm{kg})$ \\
\hline ZEN & $15.6,31.25,312.5,625$ & 31.3 & 106.1 & 0.3 & 0.1 \\
\hline$\alpha-Z E L$ & $15.6,31.25,312.5,625$ & 31.3 & 82.5 & 1.8 & 0.6 \\
\hline$\beta-Z E L$ & $15.6,31.25,312.5,625$ & 31.3 & 73 & 0.6 & 0.2 \\
\hline $\mathrm{T}-2$ & $31.25,62.5,625,1250$ & 62.5 & 107.4 & 0.4 & 0.1 \\
\hline $\mathrm{FB}_{1}$ & $15.6,31.25,312.5,625$ & 31.3 & 115.8 & 63.9 & 19.4 \\
\hline $\mathrm{FB}_{2}$ & $15.6,31.25,312.5,625$ & 31.3 & 119.2 & 2.2 & 0.7 \\
\hline $\mathrm{FB}_{3}$ & $15.6,31.25,312.5,625$ & 31.3 & 112.4 & 0.2 & 0.1 \\
\hline $\mathrm{AFB}_{1}$ & $6.25,12.5,125,250$ & 12.5 & 92.2 & 0.1 & 0.04 \\
\hline $\mathrm{AFB}_{2}$ & $6.25,12.5,125,250$ & 12.5 & 109.3 & 0.1 & 0.02 \\
\hline $\mathrm{AFG}_{1}$ & $6.25,12.5,125,250$ & 12.5 & 132.3 & 0.2 & 0.1 \\
\hline $\mathrm{AFG}_{2}$ & $6.25,12.5,125,250$ & 12.5 & 76.8 & 0.3 & 0.1 \\
\hline AME & $31.25,62.5,625,1250$ & 62.5 & 89.6 & 1.1 & 0.3 \\
\hline HT-2 & $31.25,62.5,625,1250$ & 62.5 & 117.7 & 0.5 & 0.2 \\
\hline DON & $31.25,62.5,625,1250$ & 62.5 & 112 & 8.3 & 2.5 \\
\hline 3-ADON & $31.25,62.5,625,1250$ & 62.5 & 127 & 0.2 & 0.1 \\
\hline 15-ADON & $31.25,62.5,625,1250$ & 62.5 & 97 & 5.7 & 1.7 \\
\hline
\end{tabular}

3-ADON:3-Acetyldeoxynivalenol, 15-ADON: 15-Acetyldeoxynivalenol, DON: Deoxynivalenol, $\alpha$-ZEL: $\alpha$-Zearalenol, ZEN: Zearalenone, $\beta$-ZEL: $\beta$-Zearalenol, $\mathrm{FB}_{1}$ : Fumonisin $\mathrm{B}_{1}, \mathrm{FB}_{2}$ : Fumonisin $\mathrm{B}_{2}, \mathrm{FB}_{3}$ : Fumonisin $\mathrm{FB}_{3}$, $\mathrm{T}-2$ : $\mathrm{T}-2$ toxin, HT-2: HT-2 toxin, $\mathrm{AFB}_{1}$ : Aflatoxins $\mathrm{B}_{1}, \mathrm{AFB}_{2}$ : Aflatoxin $\mathrm{B}_{2}, \mathrm{AFG}_{1}$ : Aflatoxin $\mathrm{G}_{1}$ and $\mathrm{AFG}_{2}$ : Aflatoxin $\mathrm{G}_{2}, \mathrm{AME}$ : Alternariol monomethyl ether.

\subsection{The Incidence Levels of Mycotoxins in Poultry Feed}

The findings in the present study show that commercial poultry feeds were contaminated with multiple mycotoxins. In total, 16 mycotoxins were recovered, with $50 \%$ of the analysed samples contaminated with all 16 mycotoxins as presented in Appendix A Table A3 (raw data). Although sample size amongst the different feeds analysed was not even, the incidence of 16 mycotoxins were observed in $63 \%$ of the broiler layer feed, and in $57 \%$ of both the starter and the farmix feed. The frequencies of all 16 mycotoxins in feed for breeders, growers, and finishers were in 47,39 , and $27 \%$, respectively. A combination of significant mycotoxins, i.e., AFs, FUMs, ZEN, T-2, HT-2, DON, AME and alongside some of their metabolites ( $\alpha$-ZEL, $\beta$-ZEL, 3- and 15-ADON) co-occurred in individual poultry feed samples in this study. A summary of selected mycotoxins occurring naturally singly or in combination 
in the analysed samples is represented in Table 2. The high occurrence of $\mathrm{FB}_{1}$ followed by ZEN and DON dominated in all provinces in comparison to other mycotoxins is summarised in Table 3.

Table 2. Overview of mycotoxins levels in poultry feed samples from South Africa.

\begin{tabular}{|c|c|c|c|c|}
\hline Analyte $^{a}$ & $\begin{array}{l}\text { b \% Frequency of } \\
\text { Positive Samples }\end{array}$ & $\begin{array}{l}\text { c } \% \text { Number of Positive } \\
\text { Samples above } \geq \text { LOQ }\end{array}$ & $\begin{array}{c}{ }^{d} \text { Mean conc. } \\
(\mu \mathrm{g} / \mathrm{kg})\end{array}$ & $\begin{array}{l}\text { Max. conc. } \\
(\mu \mathrm{g} / \mathrm{kg})\end{array}$ \\
\hline ZEN & 100 & 99 & 71.2 & 428.9 \\
\hline$\alpha-Z E L$ & 100 & 99 & 5.4 & 19.9 \\
\hline$\beta-Z E L$ & 100 & 99 & 3.8 & 22.1 \\
\hline $\mathrm{T}-2$ & 100 & 100 & 3.1 & 15.3 \\
\hline $\mathrm{FB}_{1}$ & 100 & 100 & 1075.6 & 7125.3 \\
\hline $\mathrm{FB}_{2}$ & 100 & 100 & 28.5 & 125.1 \\
\hline $\mathrm{FB}_{3}$ & 100 & 100 & 22.2 & 115.1 \\
\hline Average FUMs & 100 & 100 & 375.42 & 2455.2 \\
\hline $\mathrm{AFB}_{1}$ & 93 & 98 & 0.2 & 0.9 \\
\hline $\mathrm{AFB}_{2}$ & 100 & 100 & 0.4 & 7.1 \\
\hline $\mathrm{AFG}_{1}$ & 97 & 97 & 0.7 & 5.2 \\
\hline $\mathrm{AFG}_{2}$ & 78 & 82 & 0.5 & 1.6 \\
\hline Average AFs & 92 & 97 & 0.5 & 3.7 \\
\hline HT-2 & 100 & 100 & 1.9 & 5.9 \\
\hline AME & 100 & 100 & 23.1 & 155.5 \\
\hline DON & 99 & 98 & 37.8 & 154.0 \\
\hline 3-ADON & 98 & 95 & 1.6 & 12.9 \\
\hline 15-ADON & 59 & 35 & 8.9 & 44.9 \\
\hline
\end{tabular}

3-ADON: 3-Acetyldeoxynivalenol, 15-ADON: 15-Acetyldeoxynivalenol, DON: deoxynivalenol, $\alpha$-ZEL: $\alpha$-zearalenol, ZEN: Zearalenone, $\beta$-ZEL: $\beta$-zearalenol, $\mathrm{FB}_{1}$ : fumonisin $\mathrm{B}_{1}, \mathrm{FB}_{2}$ : fumonisin $\mathrm{B}_{2}, \mathrm{FB}_{3}$ : fumonisin $\mathrm{FB}_{3}, \mathrm{~T}-2$ : $\mathrm{T}-2$ toxin, HT-2: HT-2 toxin, $\mathrm{AFB}_{1}$ : aflatoxins $B_{1}, \mathrm{AFB}_{2}$ : aflatoxin $\mathrm{B}_{2}, \mathrm{AFG}_{1}$ : aflatoxin $\mathrm{G}_{1}, \mathrm{AFG}_{2}$ : aflatoxin $\mathrm{G}_{2}$ and $\mathrm{AME}$ : alternariol monomethyl ether; ${ }^{a}$ OTA was analysed but not detected in any of the analysed samples; ${ }^{\mathrm{b}}$ Frequency of positive samples in percentage (in total 105 poultry feed were analysed); ${ }^{c}$ Number of positive samples above LOQ in percentage; ${ }^{d}$ Mean concentration levels of mycotoxins in positive samples.

The overall data revealed that all the 105 poultry feed samples analysed contained multiple mycotoxins. Figure 1 re-presents the co-occurrence of the groups of mycotoxins commonly detected in poultry feeds, which are AFs, FUMs, ZENs, DONs, HT-2 and T-2. This was achieved by calculating the frequencies of all the possible co-occurrence patterns of the mycotoxins in the samples. The highest co-occurrence of mycotoxins that appeared in the poultry feed samples was AFs, FUMs, ZENs and DONs which occurred with a frequency of $51 \%$, while the co-contamination of FUMs, ZENs and DONs occurred in $42 \%$ of the samples. A similar frequency of $26 \%$ was detected with samples concurrently contained AFs + FUMs and ZENs, and AFs + FUMs + HT-2 and T-2. In general, out of 17 mycotoxins analysed in this study, 10 mycotoxins (ZEN, $\alpha-Z E L, \beta-Z E L, \mathrm{FB}_{1}, \mathrm{FB}_{2}, \mathrm{FB}_{3}, \mathrm{AFB}_{2}$, AME, T-2 and HT-2) were individually detected in all of the poultry feed samples analysed; this excludes DON, 3-ADON, $\mathrm{AFG}_{1}, \mathrm{AFB}_{1}, \mathrm{AFG}_{2}$ and 15-ADON (Appendix A raw data Table $\mathrm{A} 3$ ). 
Table 3. Mycotoxins contamination level $(\mu \mathrm{g} / \mathrm{kg})$ in poultry feeds per province.

\begin{tabular}{|c|c|c|c|c|c|c|c|c|c|c|c|c|c|c|c|}
\hline \multirow[b]{2}{*}{ Analytes } & \multicolumn{3}{|c|}{ Gauteng (45) } & \multicolumn{3}{|c|}{ KwaZulu-Natal (26) } & \multicolumn{3}{|c|}{ Eastern Cape (5) } & \multicolumn{3}{|c|}{ Western Cape (17) } & \multicolumn{3}{|c|}{ North-West (12) } \\
\hline & Mean & $\% \mathrm{~F}$ & Max. & Mean & $\% \mathrm{~F}$ & $\operatorname{Max}$ & Mean & $\% \mathrm{~F}$ & Max & Mean & $\% \mathrm{~F}$ & $\operatorname{Max}$ & Mean & $\% \mathrm{~F}$ & $\operatorname{Max}$ \\
\hline $15 \mathrm{ACDON}$ & 5.9 & 71 & 44.9 & 7.5 & 69 & 25.5 & 3 & 20 & 11.8 & 1.6 & 35 & 9.3 & 4.5 & 25 & 30.5 \\
\hline $3 \mathrm{ACDON}$ & 1.4 & 100 & 4.7 & 0.9 & 96 & 2.5 & 2.9 & 100 & 7.4 & 2.1 & 100 & 4.5 & 2.2 & 92 & 12.9 \\
\hline DON & 43 & 100 & 154 & 23.8 & 96 & 81.4 & 45.9 & 100 & 75.8 & 34.8 & 100 & 86.6 & 46.1 & 100 & 137.8 \\
\hline ZEN & 102.3 & 100 & 429 & 60.1 & 100 & 188.1 & 93.3 & 100 & 347 & 16.8 & 100 & 156.7 & 46.1 & 100 & 187.1 \\
\hline$\alpha-Z E L$ & 6.4 & 100 & 20 & 5.3 & 100 & 12.2 & 4.8 & 100 & 6.7 & 4.2 & 100 & 13 & 4.1 & 100 & 11.4 \\
\hline$\beta$-ZEL & 2.1 & 100 & 10.9 & 4 & 100 & 18 & 4.3 & 100 & 11 & 8.3 & 100 & 22.1 & 3.1 & 100 & 9.6 \\
\hline $\mathrm{FB}_{1}$ & 1096.8 & 100 & 3904.7 & 959.7 & 100 & 3019.6 & 206.6 & 100 & 496.8 & 3604.4 & 100 & 7125.3 & 1638.2 & 100 & 3507.3 \\
\hline $\mathrm{FB}_{2}$ & 19.7 & 100 & 72 & 17.5 & 100 & 61.9 & 4.9 & 100 & 13.8 & 72.8 & 100 & 125.1 & 32.6 & 100 & 80.7 \\
\hline $\mathrm{FB}_{3}$ & 15.1 & 100 & 69.3 & 15.2 & 100 & 61.4 & 4.7 & 100 & 13.3 & 55.6 & 100 & 115.1 & 23.9 & 100 & 74.4 \\
\hline $\mathrm{T}-2$ & 3 & 100 & 15.3 & 2.8 & 100 & 10.4 & 4.3 & 100 & 11.1 & 3.8 & 100 & 134 & 2.6 & 100 & 5.5 \\
\hline HT-2 & 1.8 & 100 & 5.9 & 1.7 & 100 & 4.2 & 1.8 & 100 & 3.1 & 2.8 & 100 & 5.8 & 2 & 100 & 4.2 \\
\hline $\mathrm{AFB}_{1}$ & 0.2 & 100 & 0.5 & 0.3 & 100 & 0.9 & 0.1 & 80 & 0.2 & 0.1 & 82 & 0.3 & 0.1 & 75 & 0.3 \\
\hline $\mathrm{AFB}_{2}$ & 0.6 & 100 & 7.1 & 0.3 & 100 & 3.4 & 0.1 & 100 & 0.3 & 0.3 & 100 & 1.2 & 0.2 & 92 & 0.4 \\
\hline $\mathrm{AFG}_{1}$ & 0.8 & 93 & 3 & 0.7 & 100 & 1.8 & 1.4 & 100 & 5.2 & 0.4 & 82 & 3.1 & 0.5 & 100 & 2.5 \\
\hline $\mathrm{AFG}_{2}$ & 0.5 & 100 & 1.3 & 0.6 & 89 & 1.6 & 0.3 & 100 & 0.7 & 0.2 & 10 & 1 & 0.2 & 58 & 1.6 \\
\hline AME & 27.7 & 100 & 93.6 & 32 & 100 & 155.5 & 167 & 100 & 70.1 & 6.1 & 100 & 52.2 & 13.2 & 100 & 54.7 \\
\hline
\end{tabular}

(Total number of analysed samples); 3-ADON: 3-Acetyldeoxynivalenol, 15-ADON: 15-Acetyldeoxynivalenol, DON: deoxynivalenol, $\alpha$-ZEL: $\alpha$-zearalenol, ZEN: Zearalenone, $\beta$-ZEL: $\beta$-zearalenol, $\mathrm{FB}_{1}$ : fumonisin $\mathrm{B}_{1}, \mathrm{FB}_{2}$ : fumonisin $\mathrm{B}_{2}, \mathrm{FB}_{3}$ : fumonisin $\mathrm{FB}_{3}$, T-2: T-2 toxin, $\mathrm{HT}-2$ : HT-2 toxin, $\mathrm{AFB}_{1}$ : aflatoxins $\mathrm{B}_{1}, \mathrm{AFB}_{2}$ : aflatoxin $\mathrm{B}_{2}$, $\mathrm{AFG}_{1}$ : aflatoxin $\mathrm{G}_{1}$ and $\mathrm{AFG}_{2}$ : aflatoxin $\mathrm{G}_{2}$, AME: alternariol monomethyl ether; \%F: Percentage frequency of contaminated samples. 


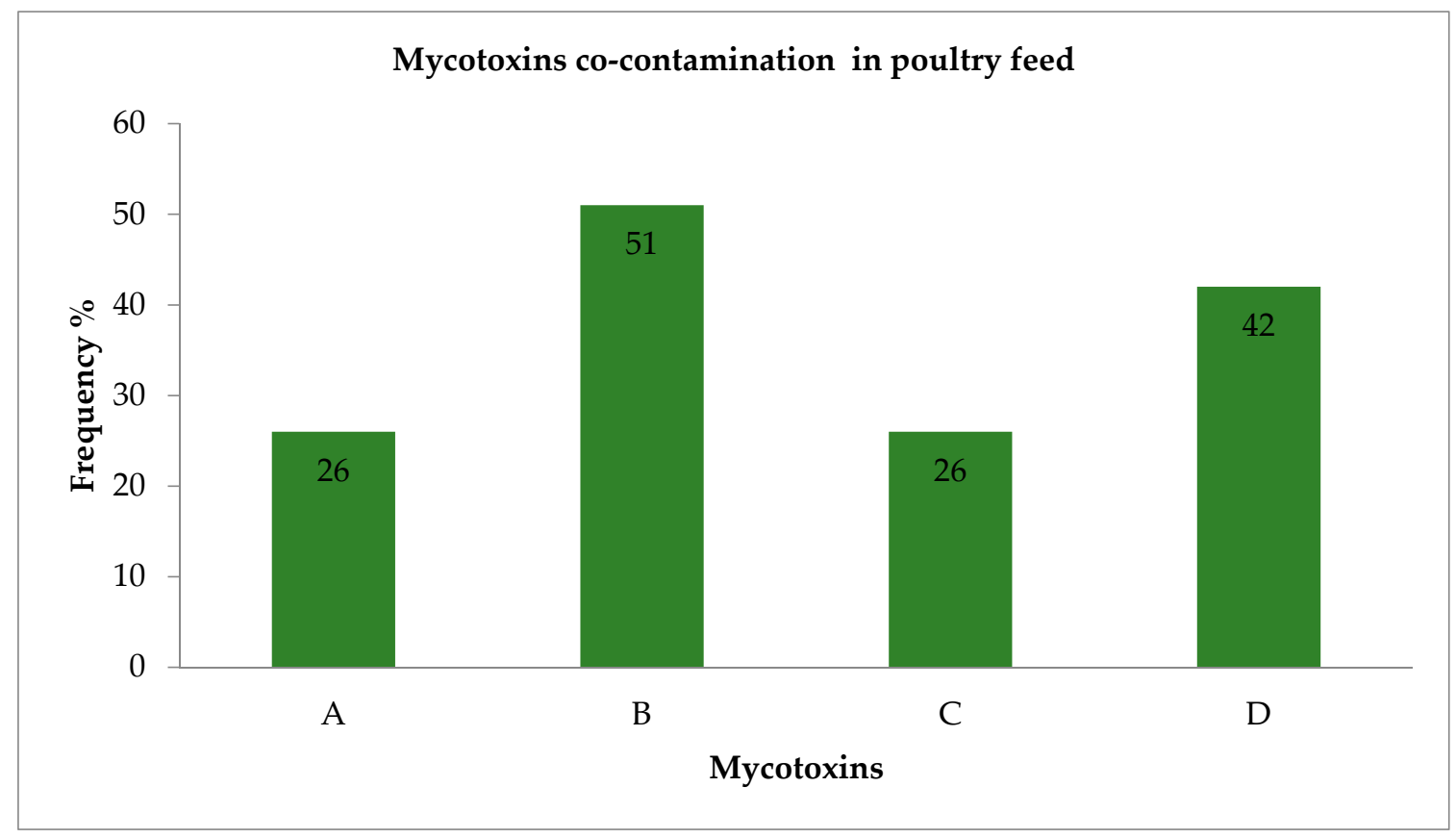

Figure 1. Mycotoxins co-contamination in poultry feed samples from selected provinces of South Africa. A: AFs + FUMs + ZENs (zearalenone and derivatives); B: AFs + FUMs + ZENs + DONs (deoxynivalenol and derivatives); C: AFs + FUMs + HT-2 + T-2; D: FUMs + ZENs + DONs at frequencies of 26, 51, 26 and $42 \%$, respectively.

\section{Discussion}

Poultry feed was analysed for mycotoxin contamination. The overall results of the reported mycotoxins in poultry feeds analysed herein are fairly in line with those of compound feeds previously analysed by Njobeh and colleagues [8], suggesting that AFs, FUMs, DON, and ZEN are the most common contaminants of poultry and other livestock feeds produced in South Africa; furthermore, reporting $\mathrm{FB}_{1}$ with higher concentration than other mycotoxins. Although the Fusarium toxins as such are predominately found as common contaminants of foods and feedstuffs mostly in maize-based products [8,9], the study on compound feeds established the high levels of FUMs in the cattle feeds and suggested that the concentration was not linked to the levels of maize as poultry feed remains the biggest consumer of maize [8]. In this study, $\mathrm{FB}_{1}, \mathrm{FB}_{2}$, and $\mathrm{FB}_{3}$ were recovered in all poultry feed samples. Fumonisin $B_{1}$ was recovered from feeds at a maximum value of $7125.3 \mu \mathrm{g} / \mathrm{kg}$ as compared to $\mathrm{FB}_{2}$ and $\mathrm{FB}_{3}$ with maximum values of 125.1 and $115.1 \mu \mathrm{g} / \mathrm{kg}$, respectively. These values are comparably higher than those previously reported in other animal feed studies conducted in the country $[8,19]$. The much higher levels of FUMs established in this study are most likely to be due to the increased inclusion of increased levels of fibre and of protein content which may be indicators of certain ingredients in different poultry feed groups (Appendix A Table A1).

Higher concentrations of $\mathrm{FB}_{1}$ compared to $\mathrm{FB}_{2}$ and $\mathrm{FB}_{3}$ are very often reported $[8,10]$. The natural occurrence of FUMs in maize and maize-based products in several African countries including South Africa is reported with these products as principal substrates $[9,25]$. Whereas this study established that the high contamination levels of FUMs are attributable to increased $\mathrm{FB}_{1}$ contamination (being at least 40 times higher than other analysed FUMs analogue), however, all the observed levels were below that regulated by the South African Department of Agriculture, Forestry and Fisheries (DAFF) set at $50,000 \mu \mathrm{g} / \mathrm{kg}$ in poultry feed [26]. Furthermore, the FUMs levels investigated herein were demonstrated to be well within the European Commission (EC) guidance values set at 20,000 $\mu \mathrm{g} / \mathrm{kg}$ for combined maximum levels of $\mathrm{FB}_{1}$ and $\mathrm{FB}_{2}$ in complementary and complete feeds for poultry [27]. The FUMs levels were also found to be well within the US Food and Drug Administration (USFDA) guidance 
levels for the sum of $\mathrm{FB}_{1}, \mathrm{FB}_{2}$ and $\mathrm{FB}_{3}$ at $30,000 \mu \mathrm{g} / \mathrm{kg}$ for breeding poultry and $100,000 \mu \mathrm{g} / \mathrm{kg}$ in feed for poultry being raised for slaughter [27].

Zearalenone and its derivatives strongly interfere with animal reproductive systems and decreased fertility [16]. Whereas currently both DAFF and USFDA do not have regulatory limits for ZEN in poultry feeds [26,27], this mycotoxin is gradually being recognized as a significant contaminant of cereal crops $[16,20]$ and it is regulated by the EC with guidance values of $2000 \mu \mathrm{g} / \mathrm{kg}$ for cereal and cereal-based products and $3000 \mu \mathrm{g} / \mathrm{kg}$ for maize products [28]. The occurrence of ZEN and its derivatives have been reported in maize and maize-products but at low concentrations [22]. Lower levels of mycotoxin derivatives are common due to possible biotransformation of the conjugated mycotoxin from the parent mycotoxin [5]. In South African studies, ZEN is reported in lower concentrations, which makes it less problematic and probably why it is not regulated in South African poultry feed $[8,20]$. In a recent South African study on multi-mycotoxins occurrence in Gauteng cattle feeds, ZEN was established in $60 \%$ samples at a mean concentration of $2.8 \mu \mathrm{g} / \mathrm{kg}$ [19], whereas Njobeh et al. [8] reported ZEN in chicken feeds with an incidence rate level of close to $52 \%$ at a maximum value of $610 \mu \mathrm{g} / \mathrm{kg}$; the levels of this toxin in our study were found in $100 \%$ tested samples to be as high as $429 \mu \mathrm{g} / \mathrm{kg}$. The derivatives of ZEN were also detected in $100 \%$ of the samples but much lower concentrations were recovered (maximum values of $22.1 \mu \mathrm{g} / \mathrm{kg}$ for $\beta$-ZEL and $20 \mu \mathrm{g} / \mathrm{kg}$ for $\alpha$-ZEL). Although they are within the EC guidance values for both cereal and maize-based products, such high levels of ZEN and its derivatives are not common in SSA. However, the world mycotoxins survey showed ZEN as the third major contaminant following DON and FUM in animal feed samples from African countries including South Africa [25].

Trichothecenes (THs) are Fusarium-derived toxins with a high potency that are commonly associated with Fusarium head blight in cereal grains [16]. Those of significance in this study were the type A TH, i.e., T-2 and HT-2 and commonly occurring type B TH DON along with its acetylated derivatives, i.e., $15-\mathrm{ADON}$ and 3-ADON. This group of mycotoxins is very common and problematic in European countries, thus considered as significant contaminants in colder European climates [9]. Hence, the EC recently placed recommended levels of $500 \mu \mathrm{g} / \mathrm{kg}$ for the sum of T-2 and HT-2 in cereal-based products and $250 \mu \mathrm{g} / \mathrm{kg}$ in compound feeds [29]. There is inadequate data on TH toxins in South Africa. None of the South African feed samples analysed previously contained either T-2, HT-2, or both, hence, there is no room for comparison on the occurrence of TH toxins in South Africa. Thus, to the best of our knowledge within the EC guidance values, this study reports for the first time, $\mathrm{T}-2$ with a range of $0.1-15.3 \mu \mathrm{g} / \mathrm{kg}$ and for the second time following a recent study on dairy cattle feed contamination [19], our study reports HT-2 (range of $0.2-5.9 \mu \mathrm{g} / \mathrm{kg}$ ) in $100 \%$ of the poultry feed samples analysed.

The incidence of DON has consistently been reported in South African crop-based products and for that reason, the mycotoxin has been of great interest in the country [8]. Department of Agriculture, Forestry and Fisheries of South Africa regulates this mycotoxin in poultry feed limiting the level to $4000 \mu \mathrm{g} / \mathrm{kg}$ [26]. In South African feedstuffs, Njobeh et al. [8] found DON in chicken feeds with mean levels of $620 \pm 386 \mu \mathrm{g} / \mathrm{kg}$ at a maximum level of $1980 \mu \mathrm{g} / \mathrm{kg}$ while Changwa et al. [19] reported lower levels of DON with a maximum value of $81.6 \mu \mathrm{g} / \mathrm{kg}$ in dairy feeds. Our study reports DON incidence of $99 \%$ but at comparatively much lower concentrations (max: $154 \mu \mathrm{g} / \mathrm{kg}$ ) than those previously reported $[8,19]$. In this study, derivatives of DON, i.e., 3-ADON and 15-ADON (max: 12.9 and $44.9 \mu \mathrm{g} / \mathrm{kg}$, respectively) were simultaneously analysed in combination, taking into consideration their isometric and co-eluting nature. The incidence levels of DON and its derivatives in this study remained well within the DAFF's maximum regulatory limits of $4000 \mu \mathrm{g} / \mathrm{kg}$ for poultry feeds [26].

Once more, this study established the natural occurrence of AME (max: $155.5 \mu \mathrm{g} / \mathrm{kg}$ ) in $100 \%$ of analysed poultry feed samples, the Alternaria toxin. There are no regulations currently available for this toxin in food or feed, however, studies have focused on establishing its profile along with alternariol $(\mathrm{AOH})$, both being the main toxins produced by Alternaria alternata most commonly encountered in fruit products, sunflower seeds, wheat and other agricultural products [10-12]. The presence of 
Alternaria toxins has been reported in maize samples $[10,11]$ and in sunflower seeds ranging between 1 and $103 \mu \mathrm{g} / \mathrm{kg}$ [12]. There is scarce data concerning levels of this toxin in toxicological studies, hence, no regulations are set currently.

Results on AFs revealed unusual occurrence patterns wherein higher concentrations of the less potent $\mathrm{AFG}_{1}$ and $\mathrm{AFG}_{2}$ (mean: 0.7 and $0.5 \mu \mathrm{g} / \mathrm{kg}$, respectively) than those of $\mathrm{AFB}_{1}$ and $\mathrm{AFB}_{2}$ (mean: 0.2 and $0.4 \mu \mathrm{g} / \mathrm{kg}$, respectively) and moreover, the G-types occurred more frequently than the B-types as observed. In animal feed, similar findings were reported [30-32], whereas, in raw maize and groundnut samples from Malawi lower mean concentrations of $A F B_{1}$ than that of $A_{F G}$ were also reported [31]. The proportion of B-types and G-types AF are highly influenced by an ecological niche of the parent fungus $[30,31]$. Aflatoxin flavus is known to be an $\mathrm{AFB}_{1}$ and $\mathrm{AFB}_{2}$ producer, while $A$. parasiticus produces all four $\mathrm{AFs}\left(\mathrm{AFG}_{1}, \mathrm{AFG}_{2}, \mathrm{AFB}_{1}\right.$, and $\left.\mathrm{AFB}_{2}\right)[17,30,31]$. Such unusual changes in $\mathrm{AFs}$ pattern may be related to climate change and global warming that could impact and compromise the behaviour of fungal plant pathogens [33]. None of the feed samples analysed was found at higher contamination level above the South African regulatory limit of $20 \mu \mathrm{g} / \mathrm{kg}$, the USFDA limit range of 10-30 $\mu \mathrm{g} / \mathrm{kg}$, and the EU regulatory limit of $2 \mu \mathrm{g} / \mathrm{kg}$ for AFs in poultry feeds [26,27].

The data demonstrated the co-occurrence of analysed metabolites at various concentrations. Mycotoxins such as DON and ZEN are both produced by Fusarium species found under cool and wet conditions [9]. Mycotoxins such as FUMs, DON and ZEN, produced by Fusarium spp. are most frequently encountered in feeds and feedstuffs [4,8,34-36]. In this study, the overall data revealed mycotoxins co-contamination of poultry feed samples (Figure 1). Based on the results of this study, exposure of individual poultry feed samples to multiple mycotoxins simultaneously is highly likely as a result of AFs, FUMs, ZENs, and DONs, as we observed co-contamination of these mycotoxins with the a higher frequency of $51 \%$. Mycotoxins can co-occur even at levels above regulatory limits very often in food and feed commodities causing negative health effects in human and animals.

A systematic review of over a hundred papers between 1987-2016, revealed 127 mycotoxin combinations, of which AFs + FBs, AFs + OTA, DON + ZEA, and FBs + ZEA were amongst the most frequently co-occurring combinations in cereal crop [27]. It has been reported that ZEA usually co-occurs with one or more of the THs, because of the ability of its producing fungi to synthesize more than one mycotoxin [16]. Mngadi et al. [23] provided some data in which several mycotoxins co-occur in feeds within the country. In our study, the co-existence of mycotoxins within the same sample was very common and data revealed that 91 samples contained multiple mycotoxins, with $67 \%$ that with 3 mycotoxins (FB + DON + ZEA), $26 \%$ with 4 mycotoxins (FB + DON + ZEA + AF).

Even though in this study, levels of the tested mycotoxins in individual samples were either below regulatory limits or at levels that could not elicit any toxic effect in poultry, a number of mycotoxins were found to co-occur with one another. Such co-occurrences of multiple mycotoxins may provoke some synergistic actions or additive effects thus, inducing various toxic effects in poultry [8]. The data reported in this study established that $51 \%$ of the samples were contaminated with multiple mycotoxins.

\section{Conclusions}

From our study, the levels of proteins in poultry feeds along with fibre content are indicators of certain ingredients which are most likely to be the reason behind the high values of mycotoxin contamination in poultry feed. In addition, some feeds are composed of raw materials, which are already contaminated, thus inevitably contributing to a high level of toxin contamination in formulated feeds. From the results obtained in this study, it can be concluded that poultry feeds are more contaminated with Fusarium mycotoxins (FUMs, ZENs, and DONs) as they were found at the highest contamination levels than other mycotoxins. The co-occurrence of multiple mycotoxins in poultry feed was noted and could pose some addictive or synergistic effects on the health and productivity of poultry. The unusual patterns of contamination of feeds by such mycotoxins as AFs, as well as the sudden appearance of AME, T-2, and HT-2 as established in this study justifies the need for feed manufacturers to monitor feed consignments for mycotoxins on a regular basis. Further to that, such findings may 
bring a shift in the implementation of management strategies for fungal and mycotoxin contamination of animal feeds in South Africa.

\section{Materials and Methods}

\subsection{Sampling}

The present study analysed different poultry feed manufactured in selected sites of South Africa, which included broiler starters, broiler growers, broiler finishers, broiler layer and broiler breeder and farmix feeds. This was mainly to assess the degree to which these agricultural products are naturally contaminated with mycotoxins. Poultry feed samples (105 in total) with an equivalent weight of $\pm 500 \mathrm{~g}$ each from five provinces of South Africa in Figure 2, namely, Gauteng (45 samples), KwaZulu-Natal (26 samples), Eastern Cape (5 samples), Western Cape (17 samples), and North West (12 samples) were donated (between May and June 2015) by a member of the South African Animal Feed Manufacturers' Association (AFMA). According to the donor, samples were randomly collected from each plant using a sampling spear from several spots within the lot and placed in sterile sealed plastic bags. The samples were further classified into six groups-broiler starter (7), broiler grower (18), broiler finisher (11), broiler breeder (15), broiler layer (8), and farmix (46) feeds. The raw material composition of the different poultry feed group is represented in Appendix A Table A1. Samples were kept in cooler boxes, transported to the University of Johannesburg and stored immediately at $-4{ }^{\circ} \mathrm{C}$ until analysed.

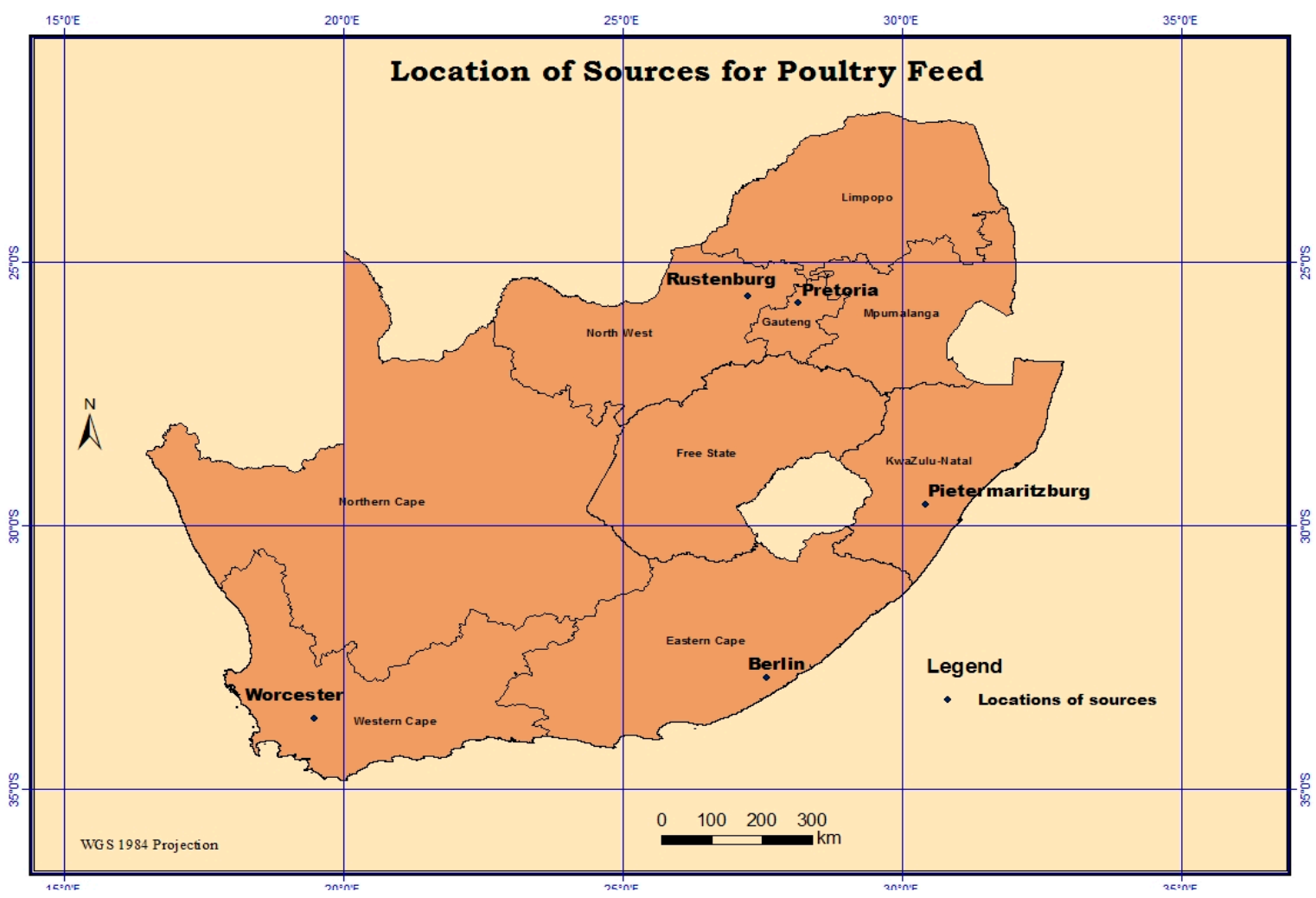

Figure 2. Poultry feed manufacturing sites in South Africa: Sampling sites are located in Pretoria (Gauteng Province), Rustenburg (North-West Province), Pietermaritzburg (KwaZulu-Natal Province), Berlin (Eastern Cape Province), and Worcester (Western Cape Province). 


\subsection{Reagents}

Liquid Chromatography grade acetonitrile $(\mathrm{ACN})$, methanol $(\mathrm{MeOH})$ and analytical grade formic acid (purity $>98 \%$ ) for organic solvents and mobile phases preparation were purchased from Sigma-Aldrich (Steinheim, Germany). Ultrapure deionized water was obtained from Millipore Milli-Q System (Merck, South Africa). Disposable Norm-Ject $10 \mathrm{~mL}$ syringe polypropylene and syringe filters $25 \mathrm{~mm}, 0.22 \mu \mathrm{m}$ filter units (Restek, Japan) were also used.

\subsubsection{Mycotoxin Standards}

The analytical standards of mycotoxins ZEN, $\alpha$-ZEL, $\beta$-ZEL, FB $1, \mathrm{FB}_{2}, \mathrm{FB}_{3}$, AME, HT-2 and T-2 toxin were obtained from Sigma-Aldrich (Steinheim, Germany), $\mathrm{AFB}_{1}, \mathrm{AFB}_{2}, \mathrm{AFG}_{1}, \mathrm{AFG}_{2}, \mathrm{DON}$, 3-ADON and 15-ADON were purchased from Trilogy ${ }^{\circledR}$ (Washington, DC, USA).

\subsubsection{Stock and Working Standard Preparation}

For experimental purposes, a combination of standard stock solution was freshly prepared for calibration purposes and spiking experiments on the least contaminated samples. Standard stock solutions were prepared into two groups: The AFs mix, which consisted of $\mathrm{AFB}_{1}, \mathrm{AFB}_{2}, \mathrm{AFG}_{1}$ and $\mathrm{AFG}_{2}$ in acetonitrile at a concentration of $250 \mu \mathrm{g} / \mathrm{kg}$ each, and the multi-mix group, also in acetonitrile consisted of $\mathrm{FB}_{1}, \mathrm{FB}_{2}, \mathrm{FB}_{3}, \mathrm{ZEN}, \alpha$-ZEL, and $\beta$-ZEL at individual concentrations of $625 \mu \mathrm{g} / \mathrm{kg}$ each; DON, 3-ADON, 15-ADON, AME, HT-2 and T-2 at $1250 \mu \mathrm{g} / \mathrm{kg}$ each. The working standard solutions were prepared by diluting the stock solutions with acetonitrile making five standard concentrations to calibrate the instrument and establish external calibration curves.

\subsection{Sample Preparation}

One-hundred and five poultry feed samples were screened for multiple mycotoxins by UHPLC-MS/MS following the dilute and shoot method [37]. Ten grams of milled dried poultry feed per sample was homogenised in a freshly prepared $40 \mathrm{~mL}$ extraction solvent consisting of acetonitrile:water:formic acid (79:20:1, v/v/v) on a bench shaker (LABCON GmbH, Heppenheim, Germany) for $60 \mathrm{~min}$ at $180 \mathrm{rpm}$ using horizontal bench shaker. The supernatant was then centrifuged (Eppendorf Millipore laboratory 5702R Centrifuge, Merck, South Africa) at $1358 \mathrm{~g}$ for $10 \mathrm{~min}$. The extracts were collected and filtered by passing through $0.22 \mu \mathrm{m}$ particle size PTFE syringe filter units, then injected into the UHPLC system.

\subsection{UHPLC-MS/MS Parameters and Analysis}

Chromatography analysis was performed using a Shimadzu UHPLC 8030 equipment coupled to an MS (Shimadzu Corporation, Tokyo, Japan) instrument capable of obtaining 500 MRMs per sec with an ultrafast scan speed of $15,000 \mathrm{u} / \mathrm{s}$, and a polarity switching of $15 \mathrm{~s}$. The chromatographic separation was achieved on an LC-30AD Nexera, which was connected to a SIL-30 AC Nexera autosampler and a CTO-20 AC Prominence Column Oven. The oven was equipped with a Raptor ${ }^{\mathrm{TM}}$ ARC-18 column from Restek $(2.7 \mu \mathrm{m}, 2.1 \times 100 \mathrm{~mm})$ (Restek Corporation, Garden City, Bellefonte, PA, USA). The column was maintained at a constant temperature of $40{ }^{\circ} \mathrm{C}$. The elution solvents mobile phase consisted of A ( $0.1 \%$ formic acid in deionized water) and B $(0.1 \%$ formic acid in acetonitrile: methanol $(50: 50, v / v))$ was delivered at a constant flow rate of $200 \mu \mathrm{L} / \mathrm{min}$. The elution gradient program had a total run time of $17 \mathrm{~min}$ and started with $10 \%$ B for $0.1 \mathrm{~min}$, increased steadily to $95 \% \mathrm{~B}$ at $8.4 \mathrm{~min}$, at which point it was kept constant for $3 \mathrm{~min}$, and then the initial condition $(10 \% \mathrm{~B})$ was re-established for $1 \mathrm{~min}$ and the column allowed to re-equilibrate for $4.5 \mathrm{~min}$ for the next run.

Following the chromatographic separation, analytes were committed to a Shimadzu triple quad mass spectrometry detector model 8030 (Shimadzu Corporation, Kyoto, Japan) for detection and quantification. The ionization source was an electro-spray ionization (ESI) operated in a positive mode at an event time of $0.206 \mathrm{~s}$. Data was acquired by a multiple reaction monitoring (MRM) method at 
optimized MS conditions for the analytes (Table 1). The ionization source parameters were optimized, interface nebulizing gas flow rate was $3 \mathrm{~L} / \mathrm{min}$, desolvation (DL) temperature was $250{ }^{\circ} \mathrm{C}$, heat block temperature was $400^{\circ} \mathrm{C}$, and drying gas flow rate was $15 \mathrm{~L} / \mathrm{min}$.

\subsection{Method Validation and Quantification in Poultry Feed}

Validation of the method was carried out for all the mycotoxins tested [37]. For quantification purposes, external calibration curves were established based on serial dilutions of the multi-analyte standard solutions in the following ranges:

(1) $6.25,12.5,125$, and $250 \mu \mathrm{g} / \mathrm{kg}$ for $\mathrm{AFB}_{1}, \mathrm{AFB}_{2}, \mathrm{AFG}_{1}$, and $\mathrm{AFG}_{2}$

(2) $31.25,62.5,625$, and $1250 \mu \mathrm{g} / \mathrm{kg}$ for DON, 3-ADON, 15-ADON, AME, HT-2, and T-2

(3) $15.6,31.25,312.5$, and $625 \mu \mathrm{g} / \mathrm{kg}$ for $\mathrm{FB}_{1}, \mathrm{FB}_{2}, \mathrm{FB}_{3}, \mathrm{ZEN}, \alpha-\mathrm{ZEL}$, and $\beta-\mathrm{ZEL}$

Linear calibration curves were considered satisfactory when correlation coefficients $\left(\mathrm{R}^{2}\right)$ were greater than 0.99 . The apparent recovery experiments were determined in triplicates on three least contaminated samples for external calibrations by spiking $5 \mathrm{~g}$ of each with $100 \mu \mathrm{L}$ of multi-mycotoxin standards with a known concentration. Subsequently, spiked samples were mixed and kept in a fume cupboard at room temperature to establish the equilibrium between the sample matrix and the toxins. Spiked samples were extracted as described in Section 5.3 following overnight establishment. From each spiked sample, $5 \mu \mathrm{L}$ of the extract was injected into the UHPLC system. Each analyte detected was quantified by comparing its peak area on the calibration plot of the equivalent mycotoxin standard. Limits of quantification (LOQ) and detection (LOD) (Results section Table 1) were estimated using the lowest concentrations in the spiked samples estimated at a signal-to-noise ratio (S/N) of 3:1 and 10:1, respectively. The apparent recovery percentage (\%R) for 16 mycotoxins extracted from each spiked matrix were determined and calculated following the Equation (1):

$$
\% \mathrm{R}=\frac{\text { mycotoxin in spiked sample }- \text { mycotoxin in not spiked sample }}{\text { Spiked mycotoxin }} \times 100
$$

Author Contributions: Conceptualization: S.M.M., S.G., and R.N.C., designed and performed the experiment; S.M.M., and R.N.C., analysed the data; S.M.M., wrote the manuscript; P.B.N. and J.Z.P. supervised the study, writing-review, edited and approved the final manuscript.

Funding: This research was funded by National Research Foundation (NRF) via the Research and Technology Funding [Grant number: PR_RTF180116305888].

Acknowledgments: The authors would like to thank Riaan Meyer and Darryl Harris from Shimadzu, South Africa, for their technical assistance on the use of LC-MS/MS instrument. The National Research Foundation (NRF) of South Africa is also acknowledged for funding this work.

Conflicts of Interest: The authors declare no conflict of interest.

\section{Appendix A}

Table A1. The composition of different poultry feed groups.

\begin{tabular}{cccc}
\hline Poultry Feed Groups & Protein Content $\mathbf{( g / k g )}$ & Fibre Content (g/kg) & Mycotoxins Incidence (\%) \\
\hline Broiler starter & 180 & 70 & 57 \\
Broiler grower/developer & 150 & 70 & 39 \\
Broiler finisher & 150 & 70 & 27 \\
Broiler layer & $155-420$ & 70 & 63 \\
Broiler breeder & $145-150$ & 70 & 47 \\
Farmix & $290-420$ & $100-150$ & 57 \\
\hline
\end{tabular}

Other contents in feed composition: $120 \mathrm{~g} / \mathrm{kg}$ maximum moisture content; $15-25 \mathrm{~g} / \mathrm{kg}$ minimum fat; $5.5-15.5 \mathrm{~g} / \mathrm{kg}$ minimum lysine; 3-4.5 g/kg minimum methionine; 8-104 g/kg calcium; phosphorus 5-14.1 g/kg. 
Table A2. Multiple reaction monitoring (MRM) transitions, MS conditions and retention (RT) times of the determined mycotoxins.

\begin{tabular}{|c|c|c|c|c|c|c|}
\hline Mycotoxin & RT (min) & Precursor $(m / z)$ & Products $(m / z)$ & Q1 Pre Bias (V) & $\mathrm{CE}$ & Q3 Pre Bias (V) \\
\hline \multirow[t]{2}{*}{ 15-ADON } & 6.54 & 355.9 & 260.9 & -2 & -16 & -30 \\
\hline & & & 136.9 & -26 & -20 & -22 \\
\hline \multirow[t]{2}{*}{ 3-ADON } & 6.589 & 338.9 & 231 & -24 & -15 & -22 \\
\hline & & & 213 & -12 & -17 & -20 \\
\hline \multirow[t]{2}{*}{$\mathrm{HT}-2$} & 8.817 & 425 & 263 & -20 & -12 & -18 \\
\hline & & & 104.9 & -16 & -47 & -19 \\
\hline \multirow[t]{2}{*}{$\mathrm{AFG}_{2}$} & 7.507 & 331 & 245.1 & -12 & -32 & -24 \\
\hline & & & 313 & -12 & -24 & -20 \\
\hline \multirow[t]{2}{*}{$\mathrm{AFG}_{1}$} & 7.767 & 329 & 243 & -12 & -28 & -23 \\
\hline & & & 311.1 & -16 & -24 & -14 \\
\hline \multirow[t]{2}{*}{$\mathrm{AFB}_{1}$} & 8.25 & 313 & 241 & -22 & -41 & -23 \\
\hline & & & 285.1 & -22 & -24 & -29 \\
\hline \multirow[t]{2}{*}{$\mathrm{FB}_{3}$} & 8.754 & 706.3 & 336.3 & -40 & -39 & -11 \\
\hline & & & 354.4 & -20 & -35 & -24 \\
\hline \multirow[t]{2}{*}{$\mathrm{FB}_{2}$} & 8.95 & 706.1 & 336.3 & -20 & -38 & -22 \\
\hline & & & 318.3 & -26 & -41 & -22 \\
\hline \multirow[t]{2}{*}{$\beta-Z E L$} & 8.949 & 323.1 & 277.2 & -16 & -16 & -18 \\
\hline & & & 305.2 & -16 & -11 & -20 \\
\hline \multirow[t]{2}{*}{$\alpha-Z E L$} & 9.415 & 323.1 & 277.2 & -17 & -17 & -18 \\
\hline & & & 305.2 & -24 & -9 & -20 \\
\hline \multirow[t]{2}{*}{$\mathrm{T}-2$} & 9.674 & 467.2 & 245.1 & -13 & -11 & -16 \\
\hline & & & 305.2 & -22 & -11 & -20 \\
\hline \multirow[t]{2}{*}{ ZEN } & 10.063 & 319.1 & 185 & -12 & -27 & -30 \\
\hline & & & 187.1 & -15 & -21 & -19 \\
\hline \multirow[t]{2}{*}{ AME } & 10.125 & 273 & 128.1 & -10 & -49 & -21 \\
\hline & & & 115.1 & -18 & -54 & -19 \\
\hline \multirow[t]{3}{*}{ DON } & 3.874 & 297.1 & 231 & -21 & -13 & -26 \\
\hline & & & 249.1 & -14 & -12 & -25 \\
\hline & & & 221 & -12 & -38 & -21 \\
\hline \multirow[t]{2}{*}{$\mathrm{FB}_{1}$} & 7.97 & 722.2 & 352.2 & -34 & -42 & -11 \\
\hline & & & 334.3 & -20 & -42 & -11 \\
\hline \multirow[t]{2}{*}{$\mathrm{AFB}_{2}$} & 8.007 & 315 & 259.1 & -22 & -31 & -25 \\
\hline & & & 287 & -23 & -26 & -30 \\
\hline
\end{tabular}

3-ADON: 3-Acetyldeoxynivalenol, 15-ADON: 15-Acetyldeoxynivalenol, DON: Deoxynivalenol, $\alpha$-ZEL: $\alpha$-Zearalenol, ZEN: Zearalenone, $\beta$-ZEL: $\beta$-Zearalenol, $\mathrm{FB}_{1}$ : Fumonisin $\mathrm{B}_{1}, \mathrm{FB}_{2}$ : Fumonisin $\mathrm{B}_{2}, \mathrm{FB}_{3}$ : Fumonisin $\mathrm{FB}_{3}$, $\mathrm{T}-2$ : $\mathrm{T}-2$ toxin, HT-2: HT-2 toxin, $A_{F B}$ : Aflatoxins $B_{1}, A_{2} B_{2}$ : Aflatoxin $B_{2}, A_{F G}$ : Aflatoxin $G_{1}$ and $A_{F G}$ : Aflatoxin $G_{2}$, and AME: Alternariol monomethyl ether. 
Table A3. Mycotoxins concentrations $(\mu \mathrm{g} / \mathrm{kg})$ in poultry feed samples from South Africa.

\begin{tabular}{|c|c|c|c|c|c|c|c|c|c|c|c|c|c|c|c|c|c|}
\hline Sample No. \# & ${ }^{*}$ Province & 15ACDON & 3ACDON & DON & $\alpha-Z E L$ & ZEN & $\beta$-ZEL & $\mathrm{FB}_{1}$ & $\mathrm{FB}_{2}$ & $\mathrm{FB}_{3}$ & $\mathrm{~T}-2$ & HT-2 & $\mathrm{AFB}_{1}$ & $\mathrm{AFB}_{2}$ & $\mathrm{AFG}_{1}$ & $\mathrm{AFG}_{2}$ & AME \\
\hline $117 \mathrm{~L}$ & KZN & ND & 0.5 & 11 & 6.8 & 148.4 & 0.8 & 38.7 & 1.1 & 0.9 & 2.5 & 0.5 & 0.5 & 0.1 & 0.4 & 0.7 & 97.3 \\
\hline $52 \mathrm{G}$ & NW & ND & 0.6 & 23.1 & 2.7 & 1.4 & 2.4 & 1127.7 & 25.2 & 23.1 & 1.8 & 4.2 & 0.1 & 0.4 & 0.1 & ND & 0.7 \\
\hline $33 \mathrm{G}$ & WC & ND & 2.4 & 17.8 & 3 & 1.6 & 13.9 & 5039.7 & 116 & 113.1 & 0.7 & 3.3 & 0.3 & 0.1 & 0.4 & ND & 0.6 \\
\hline $120 \mathrm{R}$ & GP & 2.5 & 3.6 & 92.2 & 7.3 & 148 & 1.4 & 508.4 & 10.5 & 9.8 & 4.8 & 1.9 & 0.2 & 0.1 & 0.2 & 0.5 & 29.2 \\
\hline $103 \mathrm{R}$ & GP & ND & 2.2 & 41.5 & 1.4 & 1.6 & 2 & 3904.7 & 70.5 & 69.3 & 6.2 & 0.7 & 0.1 & 0.2 & 0.1 & 0.3 & 29.5 \\
\hline $112 \mathrm{~L}$ & $\mathrm{KZN}$ & 5.9 & 0.4 & 9.2 & 2.9 & 31.2 & 1.2 & 794.6 & 12.8 & 11.6 & 2.2 & 0.9 & 0.3 & 0.1 & 1.3 & 0.7 & 23.1 \\
\hline $34 \mathrm{~F}$ & WC & 9.3 & 3.8 & 86.6 & 1.4 & 0.5 & 11.9 & 4364.9 & 98.6 & 93.6 & 1 & 2.6 & ND & 0.1 & 0.1 & 0.2 & 0.8 \\
\hline $104 \mathrm{G}$ & KZN & 4.7 & 2.5 & 49 & 4.3 & 100.7 & 1.4 & 272.5 & 6 & 5.9 & 3.7 & 1.5 & 0.5 & 0.1 & 0.4 & 0.6 & 44.8 \\
\hline $28 \mathrm{R}$ & WC & 2.6 & 0.4 & 28.6 & 13 & 7.3 & 1.4 & 1486.1 & 30.1 & 28.5 & 2.3 & 1.4 & 0.1 & 0.2 & 0.3 & ND & 1 \\
\hline $67 \mathrm{~F}$ & GP & ND & 1.7 & 17.2 & 2.9 & 34.7 & 3 & 174.5 & 3.7 & 3.3 & 3.8 & 1.7 & 0.4 & 0.1 & 0.2 & 1.3 & 41.5 \\
\hline $19 \mathrm{R}$ & WC & 7.5 & 2.3 & 16.4 & 7.8 & 156.7 & 0.8 & 81.8 & 2.8 & 2.2 & 1.5 & 1 & 0.1 & 0.2 & 3.1 & 1 & 37.8 \\
\hline $113 \mathrm{G}$ & GP & 4.9 & 0.3 & 18.9 & 5.4 & 49.7 & 0.9 & 101.4 & 2.3 & 2 & 0.7 & 1.2 & 0.2 & 0.2 & 0.5 & 0.1 & 28.3 \\
\hline $140 \mathrm{R}$ & GP & 8.2 & 2 & 54.3 & 2.2 & 57.5 & 2.6 & 2699.4 & 55.9 & 58.2 & 1.6 & 1.5 & 0.2 & 0.2 & 0.6 & 0.4 & 53.8 \\
\hline $53 \mathrm{R}$ & NW & 2.5 & 0.4 & 82.7 & 6 & 127.7 & 1.5 & 3507.3 & 80.7 & 74.4 & 3.7 & 1.1 & 0.1 & 0.4 & 0.5 & 0.3 & 11.8 \\
\hline $38 \mathrm{~S}$ & $\mathrm{EC}$ & 11.8 & 7.4 & 75.8 & 5.3 & 0.9 & 2.1 & 100 & 2.9 & 2.9 & 2.6 & 3.1 & ND & 0.1 & 0.3 & 0.3 & 1.8 \\
\hline $13 \mathrm{R}$ & WC & ND & 2.2 & 24.9 & 7.6 & 8.2 & 1.2 & 1849.1 & 38.9 & 34.5 & 3.2 & 0.4 & 0.1 & 0.1 & 0.5 & 0.5 & 1.5 \\
\hline $43 \mathrm{G}$ & $\mathrm{KZN}$ & ND & 0.6 & 7.3 & 1.6 & 0.2 & 10.8 & 1208.9 & 33 & 30.7 & 2.1 & 4.2 & 0.5 & 0.3 & 0.3 & ND & 1.6 \\
\hline $36 \mathrm{~B}$ & $\mathrm{EC}$ & 3 & 0.3 & 656 & 5.2 & 347 & 1.8 & 496.8 & 13.8 & 13.3 & 3.7 & 1.8 & 0.1 & 0.2 & 5.2 & ND & 9.5 \\
\hline $94 \mathrm{~B}$ & KZN & 12.4 & 0.2 & ND & 8.8 & 18.2 & 12.1 & 2025.2 & 32.1 & 30.3 & 3.5 & 0.7 & 0.1 & 0.2 & 0.8 & 0.6 & 26.0 \\
\hline $137 \mathrm{R}$ & GP & ND & 0.7 & 15 & 10.1 & 113.7 & 0.8 & 630.6 & 14.1 & 13.4 & 0.2 & 0.5 & 0.0 & 0.2 & 3 & 0.3 & 27.7 \\
\hline $21 \mathrm{~S}$ & WC & 2.2 & 1.7 & 37.5 & 2.4 & 2.5 & 8.2 & 5234 & 103.5 & 104.4 & 14 & 3.1 & 0.1 & 1.2 & ND & ND & 0.5 \\
\hline $69 \mathrm{~F}$ & GP & 2.4 & 0.9 & 38.6 & 8.7 & 12.8 & 0.6 & 1316.0 & 26.9 & 26.1 & 4.2 & 3.2 & 0.1 & 2 & 0.3 & 0.6 & 71.1 \\
\hline $116 \mathrm{G}$ & KZN & 24.6 & 1.1 & 81.4 & 8.5 & 108.2 & 1.2 & 116.4 & 2.6 & 3 & 2.1 & 0.9 & 0.9 & 0.1 & 0.2 & 0.8 & 44.2 \\
\hline $105 \mathrm{R}$ & GP & 20.9 & 1.2 & 154 & 5.6 & 125.3 & 4 & 638.9 & 16.8 & 14.3 & 2.6 & 1.5 & 0.2 & 0.1 & 0.6 & 0.7 & 42 \\
\hline $16 \mathrm{R}$ & WC & ND & 1.4 & 13.3 & 3 & 0.1 & 1.9 & 1342.3 & 27 & 25.7 & 4.8 & 2.2 & ND & 0.1 & 0.1 & ND & 0.8 \\
\hline $40 \mathrm{~S}$ & KZN & 3.1 & 0.3 & 22 & 6 & 188.1 & 0.6 & 3019.6 & 61.9 & 61.4 & 2.6 & 4.1 & 0.2 & 0.6 & 0.5 & 0.2 & 17.1 \\
\hline $31 \mathrm{G}$ & WC & ND & 0.2 & 19.2 & 4.2 & 1.6 & 12.1 & 4983.7 & 110.5 & 100.3 & 9.2 & 4.2 & 0.1 & 0.5 & ND & 0.4 & 0.6 \\
\hline $76 \mathrm{R}$ & GP & 6.4 & 0.8 & 25.5 & 5.4 & 89.1 & 10.9 & 168.4 & 3.8 & 0.9 & 2.5 & 0.6 & 0.1 & 0.2 & 0.5 & 0.7 & 93.6 \\
\hline $128 \mathrm{~F}$ & GP & 6.2 & 2.9 & 54.1 & 7.6 & 101.5 & 1.2 & 290.2 & 5.3 & 5.1 & 0.7 & 1.7 & 0.1 & 0.4 & 0.6 & 1 & 34.4 \\
\hline 98 B & NW & 4 & 0.3 & 13.6 & 2.4 & 50.3 & 1.3 & 642.8 & 11.5 & 10.1 & 0.9 & 0.6 & ND & 0.1 & 1.3 & 1.6 & 22.8 \\
\hline $27 \mathrm{R}$ & WC & ND & 2.2 & 19.9 & 2.1 & 15.5 & 1.9 & 903.4 & 21 & 4.8 & 0.5 & 3.5 & 0.2 & 0.6 & 0.1 & 0.3 & 0.96 \\
\hline $55 \mathrm{~F}$ & NW & ND & 0.1 & 84.7 & 3 & 5.3 & 2.8 & 2339.5 & 45.7 & 11.5 & 5.4 & 0.3 & ND & 0.3 & 0.1 & ND & 2.8 \\
\hline $119 \mathrm{~S}$ & GP & 5.3 & 4.7 & 147.8 & 20 & 107.2 & 1.4 & 861.5 & 17.6 & 16.7 & 3.5 & 3.1 & 0.3 & 0.1 & 0.6 & 1.1 & 9.8 \\
\hline $143 \mathrm{~B}$ & KZN & 17.5 & 0.5 & 27.8 & 7.4 & 119.5 & 1.3 & 375.5 & 8 & 2.3 & 10.4 & 1.3 & 0.5 & 0.1 & 0.2 & 1.3 & 155.5 \\
\hline $50 \mathrm{G}$ & GP & 3.2 & 0.3 & 42.4 & 1.3 & 136 & 0.6 & 202.6 & 4.8 & 1 & 3.2 & 1.4 & 0.3 & 0.2 & 0.4 & ND & 15.5 \\
\hline $126 \mathrm{R}$ & GP & 4.7 & 0.9 & 12.1 & 2.8 & 91.1 & 1.5 & 45.7 & 1.4 & 0.3 & 4.4 & 2.2 & 0.4 & 0.2 & 1.2 & 0.3 & 30.5 \\
\hline $142 \mathrm{~S}$ & $\mathrm{KZN}$ & 16 & 2.3 & 31.4 & 5.5 & 37.8 & 4.9 & 307.1 & 4 & 0.8 & 1 & 0.8 & 0.1 & 0.1 & 0.8 & 1.2 & 25.9 \\
\hline
\end{tabular}


Table A3. Cont.

\begin{tabular}{|c|c|c|c|c|c|c|c|c|c|c|c|c|c|c|c|c|c|}
\hline Sample No. \# & ${ }^{*}$ Province & 15ACDON & 3ACDON & DON & $\alpha-\mathrm{ZEL}$ & ZEN & $\beta$-ZEL & $\mathrm{FB}_{1}$ & $\mathrm{FB}_{2}$ & $\mathrm{FB}_{3}$ & T-2 & HT-2 & $\mathrm{AFB}_{1}$ & $\mathrm{AFB}_{2}$ & $\mathrm{AFG}_{1}$ & $\mathrm{AFG}_{2}$ & AME \\
\hline $118 \mathrm{R}$ & GP & ND & 0.8 & 9.9 & 3.6 & 53.6 & 1.9 & 3735.5 & 72 & 20.3 & 2.8 & 2.4 & 0.1 & 0.2 & 1 & 0.2 & 7.4 \\
\hline $73 \mathrm{R}$ & GP & ND & 2.1 & 99.8 & 8.2 & 8.7 & 7.3 & 2070.4 & 47.9 & 11.3 & 0.1 & 2.3 & 0.3 & 0.1 & 0.2 & 0.6 & 1.5 \\
\hline $133 \mathrm{~F}$ & GP & 2.7 & 0.6 & 42 & 17.3 & 33.6 & 1.4 & 98.9 & 2.1 & 0.3 & 4.5 & 2.4 & 0.3 & 0.1 & 0.2 & 0.8 & 15.9 \\
\hline $57 \mathrm{R}$ & KZN & ND & 2.1 & 33.5 & 1.1 & 111.2 & 2 & 198.6 & 3.7 & 0.9 & 3.1 & 1.3 & 0.2 & 1 & 0.2 & 0.1 & 15.8 \\
\hline $15 \mathrm{R}$ & WC & ND & 2.7 & 59.2 & 0.8 & 22.8 & 17.8 & 4223.2 & 83.6 & 22.7 & 5.8 & 5.8 & 0.1 & 1.1 & 0.3 & ND & 1 \\
\hline $29 \mathrm{G}$ & WC & ND & 1.3 & 28.5 & 3.9 & 10.8 & 8.5 & 4911.1 & 107.5 & 29.5 & 3.5 & 2.5 & ND & 0.1 & 0.2 & 0.2 & 0.9 \\
\hline $35 \mathrm{~F}$ & WC & ND & 2.8 & 67.1 & 5.2 & 1.1 & 12.1 & 4376.2 & 106.8 & 31.1 & 2.3 & 4.2 & 0.1 & 0.1 & 0.1 & ND & 1.3 \\
\hline $138 \mathrm{R}$ & GP & 6.1 & 0.8 & 56.7 & 7.9 & 117.4 & 0.5 & 1292.4 & 27.2 & 5.5 & 3.2 & 1.9 & 0.2 & 0.1 & 0.6 & 0.7 & 17.5 \\
\hline $121 \mathrm{R}$ & GP & 6.6 & 0.9 & 10.2 & 13.2 & 199.6 & 1.5 & 1528.7 & 30.7 & 8.7 & 8.2 & 1.7 & 0.5 & 0.1 & 3 & 0.4 & 30.7 \\
\hline $132 \mathrm{R}$ & GP & 2.9 & 4.3 & 88 & 3 & 3 & 3.8 & 961.2 & 19.3 & 4.9 & 0.9 & 2.3 & 0.2 & 5.2 & 0.2 & 0.2 & 0.5 \\
\hline $102 \mathrm{~L}$ & KZN & 7.7 & 0.3 & 13.5 & 7.5 & 26.6 & 1 & 980.8 & 21.2 & 4.9 & 3.6 & 0.8 & 0.2 & 0.1 & 0.7 & 0.2 & 24.1 \\
\hline $95 \mathrm{G}$ & NW & ND & 3 & 39.8 & 6.1 & 10.2 & 9.6 & 1570.6 & 32.3 & 9.6 & 0.8 & 4 & 0.2 & 0.1 & 0.1 & ND & 3.1 \\
\hline $101 \mathrm{G}$ & KZN & 18.4 & 0.4 & 37 & 6.5 & 106.5 & 0.4 & 395.1 & 7.9 & 8.1 & 1.5 & 1.1 & 0.3 & 0.1 & 0.2 & 0.2 & 42.6 \\
\hline $123 \mathrm{R}$ & GP & 7.7 & 0.4 & 11.1 & 1.9 & 80.8 & 2.4 & 114.6 & 2.7 & 0.3 & 1.7 & 1.8 & 0.1 & 0.1 & 0.3 & 0.2 & 13.2 \\
\hline $111 \mathrm{~L}$ & KZN & 11.2 & 1.5 & 4.3 & 12.2 & 48.9 & 1.3 & 44.9 & 0.7 & 0.1 & 0.9 & 2.9 & 0.3 & 0.2 & 1.5 & 0.9 & 32.7 \\
\hline $48 \mathrm{R}$ & GP & ND & 0.2 & 10.8 & 7.4 & 121.8 & 1.3 & 299.4 & 4.4 & 3.2 & 4.8 & 2 & 0.2 & 0.1 & 0.7 & 0.2 & 13.9 \\
\hline $77 \mathrm{R}$ & GP & 3.6 & 3.4 & 75.3 & 4.3 & 130.6 & 3.8 & 733.9 & 11.6 & 10.4 & 5.9 & 0.8 & 0.3 & 0.1 & 0.8 & 0.2 & 29.4 \\
\hline $97 \mathrm{~F}$ & NW & ND & 0.7 & 14.1 & 3.2 & 24.7 & 2 & 2616.3 & 48.2 & 44.4 & 5.5 & 3.1 & ND & 0.2 & 0.2 & ND & 4.4 \\
\hline $110 \mathrm{R}$ & GP & ND & 2.4 & 58.7 & 4.4 & 7.9 & 1.5 & 1092.6 & 14.9 & 14.4 & 1.3 & 2.8 & 0.3 & 7.1 & 0.1 & 0.7 & 4.1 \\
\hline $25 \mathrm{R}$ & WC & ND & 1.7 & 45.2 & 3.2 & 0.6 & 22.1 & 7125.3 & 125.1 & 115.1 & 1.2 & 3.3 & 0.1 & 0.2 & 0.2 & 0.3 & 0.8 \\
\hline $23 \mathrm{~B}$ & WC & ND & 4.5 & 17.5 & 5.1 & 11.9 & 3.8 & 2846.6 & 31.9 & 29.1 & 1.3 & 0.9 & 0.2 & 0.2 & 0.4 & ND & 0.6 \\
\hline $108 \mathrm{~L}$ & KZN & ND & 0.3 & 18.9 & 1.2 & 31.1 & 4.7 & 403.7 & 9.6 & 8.3 & 1 & 2.3 & 0.2 & 0.02 & 0.9 & 0.3 & 37.3 \\
\hline $107 \mathrm{~B}$ & KZN & ND & 0.2 & 32.8 & 3 & 62.5 & 0.6 & 1591 & 22 & 19.1 & 8.3 & 1.8 & 0.2 & 0.1 & 0.5 & 0.2 & 33.8 \\
\hline $78 \mathrm{G}$ & GP & ND & 0.2 & 10.1 & 4.9 & 102.9 & 0.6 & 39.1 & 1 & 0.8 & 1.1 & 0.2 & 0.1 & 0.1 & 1.9 & 0.3 & 31.6 \\
\hline $124 \mathrm{R}$ & GP & ND & 0.1 & 15.7 & 0.7 & 39.5 & 1.4 & 272.5 & 4.4 & 4.4 & 6.4 & 5.9 & 0.1 & 0.1 & 0.8 & ND & 2.9 \\
\hline $63 \mathrm{R}$ & GP & ND & 0.1 & 23.6 & 1.2 & 47.9 & 0.3 & 1636.7 & 21.4 & 19 & 1.0 & 2.7 & 0.1 & 0.1 & 0.9 & 0.3 & 83.4 \\
\hline $139 \mathrm{~S}$ & KZN & 5.1 & 0.5 & 42.7 & 11.5 & 25.8 & 0.4 & 1203.6 & 15.9 & 14.8 & 5.3 & 1.1 & 0.3 & 3.4 & 0.7 & 0.4 & 10 \\
\hline $81 \mathrm{R}$ & GP & 6.6 & 0.9 & 23.2 & 7.2 & 136 & 0.4 & 147.7 & 3.9 & 3.6 & 0.4 & 2.3 & 0.1 & 0.9 & 1.2 & 0.7 & 60.6 \\
\hline $62 \mathrm{~B}$ & GP & 8.2 & 0.4 & 47.4 & 9.6 & 176 & 0.8 & 45.2 & 1.1 & 0.3 & 15.3 & 1.7 & 0.2 & 0.8 & 0.5 & 0.3 & 39.8 \\
\hline $75 \mathrm{~B}$ & GP & 2.5 & 1.5 & 34 & 8 & 259.4 & 0.6 & 1611.8 & 33.7 & 31.1 & 1 & 0.8 & 0.3 & 0.1 & 1.9 & 0.4 & 38.3 \\
\hline $74 \mathrm{R}$ & GP & 2.7 & 0.2 & 28.9 & 5.3 & 141.7 & 1.4 & 1356.8 & 22.9 & 22.3 & 1.7 & 0.7 & 0.3 & 0.3 & 0.2 & 0.2 & 25.4 \\
\hline $24 \mathrm{R}$ & WC & 5 & 1.5 & 39.8 & 5.5 & 10.9 & 1.6 & 1333 & 22.2 & 19.7 & 5.9 & 1.9 & 0.1 & 0.1 & 0.2 & ND & 0.3 \\
\hline $115 \mathrm{~B}$ & GP & ND & 0.4 & 65.8 & 14.8 & 41.4 & 0.8 & 844.8 & 13.3 & 12.1 & 4.5 & 1.1 & 0.2 & 0.7 & 0.1 & 0.2 & 17.2 \\
\hline $79 \mathrm{R}$ & GP & 41.9 & 2.7 & 50.4 & 10.2 & 195.9 & 0.8 & 146.3 & 2.1 & 0.1 & 0.9 & 2.6 & 0.2 & 0.1 & 1.4 & 1.2 & 32.7 \\
\hline $96 \mathrm{~B}$ & NW & 30.5 & 0.7 & 42.3 & 11.4 & 141.1 & 1.8 & 1009.4 & 18.4 & 0.1 & 1.9 & 0.4 & 0.3 & 0.2 & 1.1 & 0.3 & 54.7 \\
\hline $44 \mathrm{~L}$ & KZN & 7.5 & 2.0 & 9.6 & 6.3 & 34.2 & 3.5 & 678.6 & 14.7 & 13.1 & 0.6 & 1.1 & 0.2 & 0.1 & 1 & 0.3 & 9.8 \\
\hline $136 \mathrm{R}$ & GP & 17.4 & 0.7 & 8.3 & 3.7 & 102.6 & 1.2 & 927.9 & 14.6 & 12.8 & 1.3 & 1 & 0.3 & 0.1 & 0.6 & 0.6 & 47.4 \\
\hline $106 \mathrm{G}$ & KZN & 7.9 & 1.5 & 41.1 & 5.5 & 78.3 & 1.5 & 703.4 & 11.4 & 10.3 & 0.5 & 2 & 0.3 & 0.0 & 0.6 & ND & 33.7 \\
\hline $37 \mathrm{~L}$ & EC & ND & 3.6 & 49.8 & 6.7 & 1 & 11 & 66.5 & 1.4 & 1.5 & 3.4 & 2.1 & 0.1 & 0.1 & 0.3 & 0.7 & 1.1 \\
\hline
\end{tabular}


Table A3. Cont.

\begin{tabular}{|c|c|c|c|c|c|c|c|c|c|c|c|c|c|c|c|c|c|}
\hline Sample No. \# & * Province & 15ACDON & 3ACDON & DON & $\alpha$-ZEL & ZEN & $\beta$-ZEL & $\mathrm{FB}_{1}$ & $\mathrm{FB}_{2}$ & $\mathrm{FB}_{3}$ & T-2 & HT-2 & $\mathrm{AFB}_{1}$ & $\mathrm{AFB}_{2}$ & $\mathrm{AFG}_{1}$ & $\mathrm{AFG}_{2}$ & AME \\
\hline $42 \mathrm{G}$ & KZN & ND & ND & 2.5 & 0.8 & 2.4 & 10.1 & 2587.5 & 54.3 & 50.9 & 0.7 & 2.8 & 0.1 & 0.1 & 0.4 & 0.2 & 1.6 \\
\hline $32 \mathrm{~F}$ & WC & ND & 2.5 & 49.3 & 2.5 & 5.7 & 11.9 & 6220.3 & 123.1 & 112.8 & 5.9 & 4.2 & 0.1 & 0.3 & 0.3 & ND & 2.4 \\
\hline $80 \mathrm{R}$ & GP & 4.4 & 1.3 & 21.4 & 13.8 & 244.3 & 4.3 & 82.7 & 1.6 & 0.1 & 0.8 & 1 & 0.2 & 0.1 & 1.2 & 0.4 & 32 \\
\hline $70 \mathrm{~B}$ & GP & ND & 0.4 & 71.3 & 9.5 & 6.4 & 0.3 & 3640.1 & 54.6 & 50.3 & 6.4 & 1.7 & 0.5 & 0.1 & 0.4 & 0.3 & 1.4 \\
\hline $22 \mathrm{R}$ & WC & ND & 1.7 & 20.5 & 1.2 & 26.9 & 9.8 & 4953.7 & 88.9 & 77.8 & 1.1 & 3.9 & 0.1 & 0.1 & ND & ND & 52.2 \\
\hline $141 \mathrm{R}$ & GP & 2.7 & 0.2 & 36.2 & 0.6 & 93.3 & 0.2 & 2932.7 & 48.1 & 44 & 2.5 & 2.6 & 0.5 & 2.8 & 0.7 & 0.6 & 5.4 \\
\hline $100 \mathrm{~B}$ & KZN & 25.5 & 0.4 & 36 & 2.1 & 81.1 & 3.7 & 818.2 & 12.7 & 12 & 4.0 & 0.7 & 0.4 & 0.2 & 1.8 & 0.1 & 37 \\
\hline $45 \mathrm{~F}$ & KZN & ND & 2 & 11.8 & 0.7 & 1.1 & 13.8 & 703.3 & 14.8 & 13.4 & 2.1 & 4.2 & 0.1 & 0.1 & 0.4 & 0.6 & 1.7 \\
\hline $39 \mathrm{G}$ & EC & ND & 0.8 & 19.1 & 4.3 & 93.8 & 1.1 & 142 & 2.6 & 2.1 & 11.1 & 1.2 & 0.2 & 0.3 & 0.9 & 0.2 & 70.1 \\
\hline $56 \mathrm{R}$ & NW & ND & 3.4 & 30.5 & 2.8 & 3.7 & 1.5 & 1542.6 & 30.2 & 28.5 & 0.8 & 3.4 & 0.1 & 0.1 & 0.1 & ND & 49.8 \\
\hline $59 \mathrm{G}$ & NW & 6.8 & 1.9 & 48.5 & 2.2 & 187.1 & 1.3 & 1317.8 & 23 & 19.4 & 1.5 & 1.9 & 0.2 & 0.3 & 2.5 & 0.1 & 4.3 \\
\hline $49 \mathrm{R}$ & GP & ND & 3.5 & 42.5 & 0.7 & 7.9 & 4.5 & 3316.3 & 61.5 & 57.1 & 1.2 & 0.8 & 0.1 & 0.1 & 0.7 & ND & 1.6 \\
\hline $58 \mathrm{R}$ & NW & ND & ND & 4.2 & 3.4 & 1 & 1.9 & 1732.5 & 34.1 & 32 & 4.2 & 1.4 & 0.1 & 0.2 & 0.1 & ND & 1.6 \\
\hline $66 \mathrm{~B}$ & GP & 7.2 & 1 & 8.7 & 2.7 & 69.4 & 1.3 & 2805.3 & 46.5 & 47.8 & 1 & 1.4 & 0.2 & 0.3 & 1 & 0.6 & 17.7 \\
\hline $92 \mathrm{~L}$ & KZN & 3.6 & 0.8 & 5.9 & 6.1 & 19.3 & 1.3 & 872.9 & 15.3 & 13.6 & 3.1 & 1.2 & 0.1 & 0.2 & 0.4 & 1.6 & 20.9 \\
\hline $130 \mathrm{R}$ & GP & 5.1 & 1.7 & 30.5 & 5.1 & 137.5 & 1.4 & 135.2 & 4.1 & 3.9 & 4.1 & 1.2 & 0.4 & 0.1 & 0.2 & 0.7 & 40.9 \\
\hline $60 \mathrm{~B}$ & NW & ND & 2.1 & 31.9 & 1.4 & 0.6 & 2.1 & 741 & 16.6 & 12.7 & 2.8 & 0.9 & 0.1 & 0.1 & 0.2 & ND & 1.3 \\
\hline $41 \mathrm{~F}$ & KZN & ND & 2.3 & 18.4 & 4.5 & 0.2 & 18 & 1069.5 & 20.7 & 18.8 & 1.4 & 1.5 & 0.1 & 0.1 & 0.1 & 0.3 & 0.9 \\
\hline $93 \mathrm{G}$ & KZN & 11.7 & 1 & 42.9 & 3 & 83.3 & 1.3 & 1509.2 & 18.7 & 17.6 & 4.4 & 1.4 & 0.2 & 0.2 & 1 & 1 & 38.6 \\
\hline $135 \mathrm{G}$ & KZN & 1.7 & 0.2 & 23.9 & 3.9 & 51.4 & 2.3 & 2436.3 & 37.8 & 32.7 & 1 & 1.7 & 0.1 & 0.2 & 1 & 0.4 & 37.5 \\
\hline $99 \mathrm{R}$ & GP & 11.8 & 0.3 & 4.4 & 5.3 & 109.5 & 1.4 & 256.9 & 5.3 & 3.5 & 0.4 & 2.8 & 0.1 & 0.1 & 0.8 & 0.2 & 22.3 \\
\hline $51 \mathrm{R}$ & GP & 3.2 & 1.6 & 35.7 & 3.7 & 429 & 0.9 & 1420.5 & 3.9 & 3.3 & 2.7 & 3.3 & 0.1 & 0.1 & 2.5 & 0.2 & 14 \\
\hline $65 \mathrm{R}$ & GP & 6.3 & 1.6 & 45.2 & 10.6 & 123.2 & 3.2 & 247.8 & 3.9 & 3.5 & 3.6 & 1.5 & 0.1 & 0.2 & 1.1 & 0.2 & 20.8 \\
\hline $122 \mathrm{R}$ & GP & 2.6 & 2.4 & 48.4 & 8.2 & 102.4 & 3.3 & 175 & 3.2 & 3.1 & 0.4 & 1.6 & 0.3 & 0.1 & 0.2 & 0.3 & 37.6 \\
\hline $127 \mathrm{R}$ & GP & 27 & 0.5 & 97.1 & 8.6 & 129.2 & 2.9 & 1232.7 & 25.1 & 20.9 & 1.4 & 0.9 & 0.1 & 0.7 & 0.7 & 0.4 & 18.7 \\
\hline $54 \mathrm{R}$ & NW & 10.1 & 12.9 & 137.8 & 4.4 & 0.4 & 9.3 & 1510.8 & 24.8 & 20.7 & 1.7 & 2.8 & 0.1 & 0.2 & 0.1 & 0.2 & 0.9 \\
\hline $47 \mathrm{~S}$ & EC & ND & 2.3 & 18.8 & 2.8 & 23.8 & 5.7 & 227.6 & 3.7 & 3.6 & 0.6 & 0.6 & 0.1 & 0.1 & 0.2 & 0.3 & 2.4 \\
\hline $64 \mathrm{R}$ & GP & 22.9 & 0.9 & 10.5 & 3 & 84.5 & 4 & 2614.4 & 41.6 & 36.7 & 2.7 & 0.8 & 0.1 & 0.6 & 1.5 & 1.0 & 15.6 \\
\hline 114 B & KZN & 9.3 & 0.9 & 5.9 & 9.7 & 45.2 & 4.1 & 598.3 & 11.8 & 10 & 1.5 & 1.9 & 0.1 & 0.2 & 1.4 & 1.4 & 18 \\
\hline Minimum & & 1.7 & 0.1 & 2.5 & 0.6 & 0.1 & 0.2 & 38.7 & 0.7 & 0.1 & 0.1 & 0.2 & 0.0 & 0.02 & 0.1 & 0.1 & 0.3 \\
\hline Maximum & & 41.9 & 12.9 & 154 & 20 & 429 & 22.1 & 7125.3 & 125.1 & 115.1 & 15.3 & 5.9 & 0.9 & 7.1 & 5.2 & 1.6 & 155.5 \\
\hline Mean & & 9 & 1.6 & 37.8 & 5.4 & 71.2 & 3.8 & 1075.6 & 28.5 & 22.2 & 3.1 & 2 & 0.2 & 0.4 & 0.7 & 0.5 & 23.1 \\
\hline Median & & 6.3 & 1 & 31 & 4.9 & 48.9 & 1.8 & 703.3 & 17.6 & 12.8 & 2.5 & 1.7 & 0.2 & 0.1 & 0.5 & 0.4 & 17.5 \\
\hline Std Dev & & 8.1 & 1.7 & 30.2 & 3.8 & 76.2 & 4.5 & 1322.7 & 31.2 & 27.2 & 2.8 & 1.2 & 0.1 & 1 & 0.8 & 0.4 & 25.1 \\
\hline \%RSD & & 8 & 1.7 & 30 & 3.8 & 75.8 & 4.4 & 1314.5 & 31.1 & 27.1 & 2.8 & 1.2 & 0.1 & 0.9 & 0.8 & 0.4 & 25 \\
\hline
\end{tabular}

* Provinces: (KZN: KwaZulu-Natal Province, NW: North West, WC: Western Cape, EC: Eastern Cape, GP: Gauteng Province). 3-ADON: 3-acetyldeoxynivalenol, 15-ADON: 15-acetyldeoxynivalenol, DON: Deoxynivalenol, $\alpha$-ZEL: $\alpha$-zearalenol, ZEN: Zearalenone, $\beta$-ZEL: $\beta$-zearalenol, $\mathrm{FB}_{1}$ : fumonisin $\mathrm{B}_{1}, \mathrm{FB}_{2}$ : fumonisin $\mathrm{B}_{2}$, FB 3 : fumonisin FB $\mathrm{B}_{3}$, T-2: T-2 toxin,

HT-2: HT-2 toxin, $A_{F B}$ : aflatoxins $B_{1}, A F B_{2}$ : aflatoxin $B_{2}, A_{F}$ : aflatoxin $G_{1}, A_{F G}$ : aflatoxin $G_{2}, A M E$ : alternariol monomethyl ether, \#: total number of feeds = 105 (S: Starters (7),

G: Grower (18), F: Finisher (11), B: Breeders (15), L: Layer (8), R: Farmix (46)), ND: not detected. 


\section{References}

1. AFMA (Animal Feed Manufacturers Association). AFMA Chairman's Report (2015/16); AFMA: Canberra, Australia, 2016. Available online: http://www.afma.co.za/afma-chairmans-report/ (accessed on 7 February 2017).

2. SAPA (South African Poultry Association). South African Poultry Association 2015 Industry Profile; SAPA: Randburg, South Africa, 2015. Available online: http://www.sapoultry.co.za/pdf-docs/sapa-industry-profile. pdf (accessed on 22 July 2017).

3. Gillespie, J.R.; Flanders, F.B. Modern Livestock and Poultry Production, 8th ed.; Cengage Learning: Clifton Park, NY, USA, 2010.

4. Zachariášová, M.; Dzuman, Z.; Vepříková, Z.; Hájková, K.; Jírů, M.; Václavíková, M.; Zachariasova, A.; Pospichalova, M.; Florian, M.; HajšLová, J. Occurrence of multiple mycotoxins in European feedingstuffs, assessment of dietary intake by farm animals. Anim. Feed. Sci. Technol. 2014, 193, 124-140. [CrossRef]

5. Bryden, W.L. Mycotoxin contamination of the feed supply chain: Implications for animal productivity and feed security. Anim. Feed. Sci. Technol. 2012, 173, 134-158. [CrossRef]

6. Rodrigues, I.; Handl, J.; Binder, E. Mycotoxin occurrence in commodities, feeds and feed ingredients sourced in the Middle East and Africa. Food Addit. Contam. Part B 2011, 4, 168-179. [CrossRef] [PubMed]

7. Greco, M.V.; Franchi, M.L.; Golba, S.L.R.; Pardo, A.G.; Pose, G.N.; Luisa, A. Mycotoxins and Mycotoxigenic Fungi in Poultry Feed for Food-Producing Animals. Sci. World J. 2014, 2014, 968215. [CrossRef] [PubMed]

8. Njobeh, P.B.; Dutton, M.F.; Åberg, A.T.; Häggblom, P. Estimation of Multi-Mycotoxin Contamination in South African Compound Feeds. Toxins 2012, 4, 836-848. [CrossRef] [PubMed]

9. Chilaka, C.A.; De Boevre, M.; Atanda, O.O.; De Saeger, S. The Status of Fusarium Mycotoxins in Sub-Saharan Africa: A Review of Emerging Trends and Post-Harvest Mitigation Strategies towards Food Control. Toxins 2017, 9, 19. [CrossRef] [PubMed]

10. Fraeyman, S.; Croubels, S.; Devreese, M.; Antonissen, G. Emerging Fusarium and Alternaria Mycotoxins: Occurrence, Toxicity and Toxicokinetics. Toxins 2017, 9, 228. [CrossRef] [PubMed]

11. Scott, P.M.; Zhao, W.; Feng, S.; Lau, B.P.-Y. Alternaria toxins alternariol and alternariol monomethyl ether in grain foods in Canada. Mycotoxin Res. 2012, 28, 261-266. [CrossRef]

12. Hickert, S.; Hermes, L.; Marques, L.M.M.; Focke, C.; Cramer, B.; Lopes, N.P.; Flett, B.; Humpf, H.-U. Alternaria toxins in South African sunflower seeds: cooperative study. Mycotoxin Res. 2017, 33, 309-321. [CrossRef]

13. Grover, S.; Lawrence, C.B. The Alternaria alternata Mycotoxin Alternariol Suppresses Lipopolysaccharide-Induced Inflammation. Int. J. Mol. Sci. 2017, 18, 1577. [CrossRef]

14. Grenier, B.; Dohnal, I.; Shanmugasundaram, R.; Eicher, S.D.; Selvaraj, R.K.; Schatzmayr, G.; Applegate, T.J. Susceptibility of Broiler Chickens to Coccidiosis When Fed Subclinical Doses of Deoxynivalenol and Fumonisins-Special Emphasis on the Immunological Response and the Mycotoxin Interaction. Toxins 2016, 8, 231. [CrossRef]

15. Shareef, A.M. Molds and mycotoxins in poultry feeds from farms of potential mycotoxicosis. Iraqi J. Vet. Sci. 2010, 24, 17-25. [CrossRef]

16. Zinedine, A.; Soriano, J.M.; Molto, J.C.; Mañes, J. Review on the toxicity, occurrence, metabolism, detoxification, regulations and intake of zearalenone: An oestrogenic mycotoxin. Food Chem. Toxicol. 2007, 45, 1-18. [CrossRef]

17. Zain, M.E. Impact of mycotoxins on humans and animals. J. Saudi Chem. Soc. 2011, 15, 129-144. [CrossRef]

18. Stoev, S.; Dutton, M.; Njobeh, P.; Mosonik, J.; Steenkamp, P. Mycotoxic nephropathy in Bulgarian pigs and chickens: Complex aetiology and similarity to Balkan Endemic Nephropathy. Food Addit. Contam. Part A 2010, 27, 72-88. [CrossRef]

19. Changwa, R.; Abia, W.; Msagati, T.; Nyoni, H.; Ndleve, K.; Njobeh, P. Multi-Mycotoxin Occurrence in Dairy Cattle Feeds from the Gauteng Province of South Africa: A Pilot Study Using UHPLC-QTOF-MS/MS. Toxins 2018, 10, 294. [CrossRef]

20. Griessler, K.A. Survey of mycotoxins in feed samples from South Africa. Pluimvee Poult. Bull. $2009,419$.

21. Dutton, M.F.; Mwanza, M.; de Kock, S.; Khilosia, L.D. Mycotoxins in South African foods: A case study on aflatoxin M1 in milk. Mycotoxin Res. 2012, 28, 17-23. [CrossRef]

22. Shephard, G.S.; Burger, H.M.; Gambacorta, L.; Gong, Y.Y.; Krska, R.; Rheeder, J.P.; Solfrizzo, M.; Srey, C.; Sulyok, M.; Visconti, A.; et al. Multiple mycotoxin exposure determined by urinary biomarkers in rural subsistence farmers in the former Transkei, South Africa. Food Chem. Toxicol. 2013, 62, 217-225. [CrossRef] 
23. Mngadi, P.T.; Govinden, R.; Odhav, B. Co-occurring mycotoxins in animal feeds. Afr. J. Biotechnol. 2008, 7, 2239-2243.

24. Iheanacho, H.E.; Njobeh, P.B.; Dutton, F.M.; Steenkamp, P.A.; Steenkamp, L.; Mthombeni, J.Q.; Daru, B.H.; Makun, A.H. Morphological and molecular identification of filamentous Aspergillus flavus and Aspergillus parasiticus isolated from compound feeds in South Africa. Food Microbiol. 2014, 44, 180-184. [CrossRef]

25. BIOMIN. Mycotoxin Report. World Mycotoxins Survey: Global Threat January to June 2017 Q1; BIOMIN Holdings GmbH: Getzersdorf, Austria, 2017; Available online: http://www.biomin.net/en/articles/biomin-worldmycotoxin-survey-q1-2017/ (accessed on 04 February 2017).

26. Government Gazette. Fertilizers, Farm Feeds, Agricultural Remedies and Stock Remedies Act (Act No. 36 of 1947); Government Gazette: Pretoria, South Africa, 2010; pp. 4-18.

27. Smith, M.C.; Madec, S.; Coton, E.; Hymery, N. Natural Co-Occurrence of Mycotoxins in Foods and Feeds and Their in vitro Combined Toxicological Effects. Toxins 2016, 8, 94. [CrossRef]

28. EC (European Commission). Commission regulation (EC) No 1126/2007 of 28 September 2007 amending Regulation (EC) No 1881/2006 setting maximum levels for certain contaminants in foodstuffs as regards Fusarium toxins in maize and maize products. Off. J. Eur. Union 2007, 255, 14-17.

29. EC (European Commission). Commission recommendation of 27 March 2013 on the presence of T-2 and HT-2 toxin in cereals and cereal products. Off. J. Eur. Union L 2013, 91, 12-15.

30. Grío, S.J.L.; Frenich, A.G.; Vidal, J.L.M.; Romero-González, R. Determination of aflatoxins B1, B2, G1, G2 and ochratoxin A in animal feed by ultra high-performance liquid chromatography-tandem mass spectrometry. J. Sep. Sci. 2010, 33, 502-508. [CrossRef]

31. Matumba, L.; Sulyok, M.; Njoroge, S.M.C.; Ediage, E.N.; Van Poucke, C.; De Saeger, S.; Krska, R. Uncommon occurrence ratios of aflatoxin B1, B2, G1, and G2 in maize and groundnuts from Malawi. Mycotoxin Res. 2014, 31, 57-62. [CrossRef]

32. Bakırdere, S.; Bora, S.; Bakırdere, E.G.; Aydın, F.; Arslan, Y.; Komesli, O.T.; Aydın, I.; Yıldırım, E.; Bakirdere, S.; Aydin, I.; et al. Aflatoxin species: their health effects and determination methods in different foodstuffs. Open Chem. 2012, 10, 675-685. [CrossRef]

33. Bebber, D.P.; Chatoner, T.; Fisher, M.L.D.C. Report from the 1st MYCOKEY International Conference Global Mycotoxin Reduction in the Food and Feed Chain Held in Ghent, Belgium, 11-14 September 2017. Toxins 2017, 9, 276.

34. Guerre, P. Worldwide Mycotoxins Exposure in Pig and Poultry Feed Formulations. Toxins 2016, 8, 350. [CrossRef]

35. Kamala, A.; Ortiz, J.; Kimanya, M.; Haesaert, G.; Donoso, S.; Tiisekwa, B.; De Meulenaer, B. Multiple mycotoxin co-occurrence in maize grown in three agro-ecological zones of Tanzania. Food Control. 2015, 54, 208-215. [CrossRef]

36. Marin, S.; Ramos, A.J.; Cano-Sancho, G.; Sanchis, V. Mycotoxins: Occurrence, toxicology, and exposure assessment. Food Chem. Toxicol. 2013, 60, 218-237. [CrossRef]

37. Kongkapan, J.; Poapolathep, S.; Isariyodom, S.; Kumagai, S.; Poapolathep, A. Simultaneous detection of multiple mycotoxins in broiler feeds using a liquid chromatography tandem-mass spectrometry. J. Vet. Med. Sci. 2016, 78, 259-264. [CrossRef]

(C) 2019 by the authors. Licensee MDPI, Basel, Switzerland. This article is an open access article distributed under the terms and conditions of the Creative Commons Attribution (CC BY) license (http://creativecommons.org/licenses/by/4.0/). 